Article

\title{
Vortex Patterns Investigation and Enstrophy Analysis in a Small Scale $\mathrm{S}-\mathrm{CO}_{2}$ Axial Turbine
}

\author{
Qiyu Ying ${ }^{1}$, Weilin Zhuge ${ }^{1, *}$, Yangjun Zhang ${ }^{1, *}$, Can Ma ${ }^{2}$, Jinlan Gou ${ }^{2, *}$ and Wei Wang ${ }^{2}$ \\ 1 State Key Laboratory of Automotive Safety and Energy, School of Vehicle and Mobility, Tsinghua University, \\ Beijing 100084, China; yingqy17@mails.tsinghua.edu.cn \\ 2 Science and Technology on Thermal Energy and Power Laboratory, Wuhan 430205, China; \\ macan1234@sina.com (C.M.); wangweirndl@sina.com (W.W.) \\ * Correspondence: zhugewl@tsinghua.edu.cn (W.Z.); yjzhang@tsinghua.edu.cn (Y.Z.); \\ gj112@tsinghua.org.cn (J.G.)
}

Citation: Ying, Q.; Zhuge, W.; Zhang, Y.; Ma, C.; Gou, J.; Wang, W. Vortex Patterns Investigation and Enstrophy Analysis in a Small Scale S- $\mathrm{CO}_{2}$ Axial Turbine. Energies 2021, 14, 6112. https://doi.org/10.3390/en14196112

Academic Editor: Theodoros Zannis

Received: 25 August 2021

Accepted: 18 September 2021

Published: 25 September 2021

Publisher's Note: MDPI stays neutral with regard to jurisdictional claims in published maps and institutional affiliations.

Copyright: (c) 2021 by the authors. Licensee MDPI, Basel, Switzerland. This article is an open access article distributed under the terms and conditions of the Creative Commons Attribution (CC BY) license (https:// creativecommons.org/licenses/by/ $4.0 /)$.
Abstract: Supercritical carbon dioxide $\left(\mathrm{S}-\mathrm{CO}_{2}\right)$ Brayton cycle system is a promising closed-loop energy conversion system frequently mentioned in the automotive and power generation field in recent years. To develop a suitable design methodology for $\mathrm{S}-\mathrm{CO}_{2}$ turbines with better performance, an understanding of the vortex flow patterns and associated aerodynamic loss inside a $\mathrm{S}-\mathrm{CO}_{2}$ turbine is essential. In this paper, a hundred-kilowatt level $\mathrm{S}-\mathrm{CO}_{2}$ axial turbine is designed and investigated using a three-dimensional transient viscous flow simulation. The NIST Span and Wagner equation of state model that considers the real gas effects is utilized to estimate the thermodynamic properties of the supercritical fluid. The numerical methods are experimentally validated. The results indicates that the aspect ratio and tip-to-hub ratio are different in the $\mathrm{S}-\mathrm{CO}_{2}$ turbine from that in the gas turbine, and the vortex flow patterns are influenced notably by these geometrical parameters. Both the vortex structure and moving tracks of passage vortices are changed as a result of large centrifugal force. An interaction between tip leakage vortex and hub passage vortex is observed in the impeller passage and its formation and development mechanism are revealed. To further explore the aerodynamic loss mechanism caused by vortex interaction, the energy loss in the impeller passage is analyzed with the enstrophy dissipation method, which can not only accurately calculate the energy loss but also estimate how the vortical motions occur. It is found that the enstrophy and energy loss can be effectively reduced by vortex interaction between tip leakage vortex and hub passage vortex. The results in this study would increase the knowledge of vortex flow patterns in $\mathrm{S}-\mathrm{CO}_{2}$ turbine and the proposed enstrophy production method can be used intuitively to provide a reference for flow vortical motion study in turbines.

Keywords: supercritical carbon dioxide; axial turbine; flow characteristic; vortex interaction; enstrophy dissipation analysis; energy loss

\section{Introduction}

Supercritical carbon dioxide $\left(\mathrm{S}-\mathrm{CO}_{2}\right)$ Brayton cycle system is a promising candidate for power converters that could potentially make the system with high thermal efficiencies, simple and compact physical layouts, and good operational flexibility in coping with the uncertain availability of any renewable energy sources. Among all the advantages of the S- $\mathrm{CO}_{2}$ Brayton cycle system, its compact size, simple structure, and closed-loop system make the $\mathrm{S}-\mathrm{CO}_{2}$ Brayton cycle suitable for the transportation field. These features are necessary advantages for the future utilizing vehicles such as flying cars and interstellar spacecraft. Multiple availabilities of many power sources like nuclear power [1-3], solar power generation $[4,5]$, gas turbines [6,7], and fuel cells [8-10] were frequently proposed dealing with $\mathrm{S}-\mathrm{CO}_{2}$ system in recent years. 
In the $\mathrm{S}-\mathrm{CO}_{2}$ Brayton cycle system, turbine performance is studied to have a more significant impact on the overall thermal efficiency of the system than those of other components [11]. In the current study, low efficiencies of $\mathrm{S}-\mathrm{CO}_{2}$ turbines have become a bottleneck that affects the small-scale $\mathrm{S}-\mathrm{CO}_{2}$ system with hundred kilowatts output power. Utamura et al. from Tokyo Institute of Technology has developed a $10 \mathrm{~kW} \mathrm{~S}-\mathrm{CO}_{2}$ power system as a lab-scale demonstration test plan [12], the designed turbine showed very low efficiency during the experimental study and only $110 \mathrm{~W}$ net power was generated and recorded [13]. The Korea Institute of Energy (KIER) has developed several S- $\mathrm{CO}_{2}$ power systems since 2013, and the $\mathrm{S}-\mathrm{CO}_{2}$ turbines were the core factor reported limiting the system performance [14-16]. No net electrical power was successfully generated from their first test loop during experiments $[16,17]$ and the updated new turbine also reported efficiency problem later [15]. Maxence et al. reported their $\mathrm{S}-\mathrm{CO}_{2}$ turbine, which was designed for a $50 \mathrm{~kW}$ power system in the European I-ThERM project, showed only 70\% isentropic efficiency in numerical simulations [18]. Wang et al. conducted several investigations on a $75 \mathrm{~kW} \mathrm{~S}-\mathrm{CO}_{2}$ turbine and CFD results indicated that turbine efficiency was only $66.27 \%$ [19]. Therefore, further study on $\mathrm{S}-\mathrm{CO}_{2}$ turbine is expected to develop a suitable design methodology for $\mathrm{S}-\mathrm{CO}_{2}$ turbines with better performance.

Some investigations have been conducted in understanding the connection between the internal flow mechanism and the aerodyanmic loss sources based on air turbines and gas turbines in the last decades. Langston et al. and other researchers have studied the multi-vortex flow in the turbine and proposed five representative models of the flow pattern [20-24]. Yamamoto, Tallman, Dreyer and other researchers have successively carried out several recognized studies on the tip leakage flow [25-28]. And different loss models were further researched based on these flow mechanism studies [29-31]. However, different from an ideal gas, supercritical carbon dioxide has a large density that is similar to those of a liquid and a low viscosity that is similar to those of a gas. The high operating pressures and densities make a significant reduction in turbine size and hence lead to high rotational speeds of the designed turbine as a result of maintaining high isentropic efficiency. Small diameter and higher rotational speeds are associated with a small blade span, low aspect ratio, high hub-to-tip ratio, and a large tip clearance ratio. All of these geometrical and operational characteristics might influence the internal flow structures, make the flow characteristics inside $\mathrm{S}-\mathrm{CO}_{2}$ turbine different from those of ideal gas turbines, and ultimately lead to remarkable aerodynamic loss.

Recognizing the importance of flow characteristic study to $\mathrm{S}-\mathrm{CO}_{2}$ turbine, some researchers started to make investigations on $\mathrm{S}-\mathrm{CO}_{2}$ turbine internal flow. To investigate the secondary flow loss mechanism in the $\mathrm{S}-\mathrm{CO}_{2}$ turbine, Han et al. have conducted several CFD simulations to study the flow characteristics of the logarithmic layer and viscous sublayer in a high-pressure $\mathrm{S}-\mathrm{CO}_{2}$ axial turbine [32]. Uusitalo et al. [33] have discussed the expansion losses distribution in a $\mathrm{S}-\mathrm{CO}_{2}$ radial inflow turbine. In the work, the loss predictions obtained with the different methods for turbine designs with varying specific speeds were compared, and high deviations of predicted rotor losses were observed, which indicated that the traditional passage loss models are not suitable for $\mathrm{S}_{-} \mathrm{CO}_{2}$ turbine. Tu et al. [34] have designed a $30 \mathrm{~kW}$ partial admission $\mathrm{S}-\mathrm{CO}_{2}$ axial turbine and analyzed its impeller aerodynamic losses. The tip leakage flow has been found to have the largest impact on turbine performance and the influence of the flow angle between the tip leakage flow and mainstream on the tip leakage flow was discussed. Ying et al. [35] have made investigations on the influence of impeller shroud structure through analyzing 4-stage $\mathrm{S}-\mathrm{CO}_{2}$ axial turbines, the influence of impeller blade tip leakage flow and shroud leakage flow has been discussed. Du et al. have studied the leakage characteristics and the effects of different seal methods in a 1.5-stage $\mathrm{S}-\mathrm{CO}_{2}$ axial-inflow turbine [36,37].

Apart from the investigations on the internal flow and aerodynamic losses in the S$\mathrm{CO}_{2}$ turbines, the design parameters and methodology were also discussed. Qi et al. from the University of Queensland have carried out studies on designing 100-200 kW S- $-\mathrm{CO}_{2}$ radial inflow turbines, the relationship between turbine geometry, loss distribution, and 
other design parameters were discussed through numerical simulations [38-40]. Wang et al. have compared and analyzed the influence of solidity structures on turbine aerodynamic performance with S- $\mathrm{CO}_{2}$ and air, respectively [41]. Salah et al. have investigated the influence of design parameters on a single-stage $100 \mathrm{~kW} \mathrm{~S}-\mathrm{CO}_{2}$ axial turbine from both mechanical and aerodynamic performance perspectives [42].

Although it is known that the $\mathrm{S}-\mathrm{CO}_{2}$ turbines have different flow structure, there is still little scientific understanding on how the internal flow characteristics in the $\mathrm{S}-\mathrm{CO}_{2}$ turbines is and how these flow influence the turbine performance. In the current paper, a $160 \mathrm{~kW}$ $\mathrm{S}-\mathrm{CO}_{2}$ axial turbine is designed and numerically investigated to explore the detailed vortex flow characteristic and associated energy loss mechanism. The numerical method was validated through the experimentally test of the designed $\mathrm{S}-\mathrm{CO}_{2}$ turbine. The formation and development of tip leakage vortex and passage vortices in the $\mathrm{S}-\mathrm{CO}_{2}$ turbine were revealed. The process of vortex interaction between tip leakage vortex and hub passage vortex was investigated. Energy loss mechanism caused by the vortex interaction was investigated through enstrophy dissipation analysis, which is method that can not only accurately calculate the energy loss but also estimate how the vortical motions occurs. The remaining part of the paper proceeds as follows: Section Two begins by laying out the theoretical dimensions of the research, including some fundamental concepts of vortex dynamic and enstrophy dissipation method. The third and fourth part give a brief overview of the designed S- $\mathrm{CO}_{2}$ turbine and the numerical method. Subsequently, detailed flow structure and vortex patterns were analyzed combined with energy loss investigation based on the simulation results. At last, some conclusions are obtained.

\section{Fundamental Theory of Vortex Dynamics}

Vortices are a special existence form of fluid motion with origin in the rotation of fluid elements. The physical quantity characterizing the rotation of fluid elements is the vorticity $(\boldsymbol{\omega}=\nabla \times \boldsymbol{u})$, but the more fundamental quantity is the velocity gradient $(\boldsymbol{A}=\nabla \boldsymbol{u})$. The intrinsic decomposition of $\nabla u$ into symmetric and antisymmetric parts gives the strainrate tensor and vorticity tensor. According to the second-order tensor calculus, there are independent invariants between the three eigenvalue equation of the $\nabla \boldsymbol{u}$, namely, the first, second, and third invariant.

$$
\begin{gathered}
P=\lambda_{1}+\lambda_{2}+\lambda_{3} \\
Q=\lambda_{1} \lambda_{2}+\lambda_{1} \lambda_{3}+\lambda_{2} \lambda_{3}=\frac{1}{2}\left[\Omega_{i j} \Omega_{i j}-e_{i j} e_{j i}\right]=\frac{1}{2}\left(\|\mathbf{\Omega}\|^{2}-\|\boldsymbol{E}\|^{2}\right) \\
R=\lambda_{1} \lambda_{2} \lambda_{3}=\frac{1}{3}\left(e_{i j} e_{j k} e_{k i}+3 \Omega_{i j} \Omega_{j k} e_{k i}\right)
\end{gathered}
$$

where

$$
\|\Omega\|^{2}=\Omega_{i j} \Omega_{i j}=\frac{1}{2}|\omega|^{2}
$$

and

$$
\|\boldsymbol{E}\|^{2}=e_{i j} e_{j i}
$$

$e_{i j}$ represents rate of strain tensor and $\Omega_{i j}$ represents vorticity tensor in the equations.

\subsection{Vortex Tracking Method}

Among three variants, $Q$ represents the extent that the amplitude of the local vorticity term exceeds that of the local strain term. In three dimensions the question on how much the vorticity should prevail over the strain rate within the eigenvalue equation may have an answer of $Q>0$, this comes to the known vortex identification method, Q-criterion [43]. 
With the additional condition that the pressure should be lower than the ambient pressure, it is believed that vortices may exist in the region with positive $Q$ values.

\subsection{Enstrophy Dissipation Analysis Method}

Enstrophy is a quantity directly related to the kinetic energy in the flow model that corresponds to dissipation effects in the fluid in vortex dynamics. It is derived from the decomposition of the strain tensor. Owing to the Föppl theorem, the integral of vorticity vector $\omega$ cannot tell the total amount of shearing in a flow domain. Thus, the enstrophy was used for such a measurement similar to the kinetic energy in turbulent flow. The effects of enstrophy play an important role in the analysis of turbulent fluid motion and energy loss, large enstrophy represents strong vortical motions which can lead to preferential concentration of inertial particles. Similar to kinetic energy, enstrophy is defined as

$$
\mathbf{\Omega}=\frac{1}{2} \int_{V} \omega^{2} \mathrm{~d} V
$$

However, as for turbulent flow, the total vorticity can be separated into two terms after the Reynolds time averaged process: the average vorticity $(\bar{\omega})$ and the fluctuating vorticity $\left(\omega^{\prime}\right)$. Correspondingly, the total enstrophy, which is denoted by $\boldsymbol{\Omega}_{t o t}$, has the following definition

$$
\boldsymbol{\Omega}_{t o t}=\frac{1}{2} \int_{V}\left(\overline{\boldsymbol{\omega}}+\boldsymbol{\omega}^{\prime}\right) \cdot\left(\overline{\boldsymbol{\omega}}+\boldsymbol{\omega}^{\prime}\right) \mathrm{d} V=\overline{\mathbf{\Omega}}+\mathbf{\Omega}^{\prime}+\int_{V} \overline{\boldsymbol{\omega}} \cdot \boldsymbol{\omega}^{\prime} \mathrm{d} V
$$

a circulation preserving flow $u$ within the equation is assumed and it is disturbed to $u=\bar{u}+u^{\prime}$ with $u^{\prime}=0$ on the boundary. The identity is used to handle the integral in the equation.

$$
\nabla \cdot\left(\boldsymbol{u}^{\prime} \times \overline{\boldsymbol{\omega}}\right)=\overline{\boldsymbol{\omega}} \cdot\left(\nabla \times \boldsymbol{u}^{\prime}\right)-\boldsymbol{u}^{\prime} \cdot(\nabla \times \overline{\boldsymbol{\omega}})
$$

since $v \nabla \times \overline{\boldsymbol{\omega}}=\nabla \sigma, \boldsymbol{u}^{\prime} \cdot \nabla \sigma=\nabla \cdot\left(\boldsymbol{u}^{\prime} \sigma\right)$ and $\boldsymbol{u}^{\prime}=0$ on $\partial V$, the integral could be obtained as

$$
\int_{V} \overline{\boldsymbol{\omega}} \cdot \boldsymbol{\omega}^{\prime} \mathrm{d} V=\int_{\partial V} \boldsymbol{n} \cdot\left(\boldsymbol{u}^{\prime} \times \overline{\boldsymbol{\omega}}-\frac{1}{v} \boldsymbol{u}^{\prime} \sigma\right) \mathrm{d} V=0
$$

Finally we acquire $\Omega_{t o t}=\bar{\Omega}+\Omega^{\prime}$, in which the $\bar{\Omega}$ represents the average enstrophy and the $\mathbf{\Omega}^{\prime}$ represents the fluctuating enstrophy generated in the turbulence flow. $\bar{\Omega}$ can be obtained from the velocity field with the modulus of vorticity,

$$
\overline{\mathbf{\Omega}}=\frac{1}{2}\left[\left(\frac{\partial \bar{w}}{\partial y}-\frac{\partial \bar{v}}{\partial z}\right)^{2}+\left(\frac{\partial \bar{u}}{\partial z}-\frac{\partial \bar{w}}{\partial x}\right)^{2}+\left(\frac{\partial \bar{v}}{\partial x}-\frac{\partial \bar{u}}{\partial y}\right)^{2}\right]
$$

while $\Omega^{\prime}$ cannot be obtained from the simulation results directly. Earlier study on the turbulence flow has proposed a relationship with large Re number

$$
\left\langle\frac{1}{2} \omega_{i}^{\prime} \omega_{i}^{\prime}\right\rangle \approx\left\langle e_{i j}^{\prime} e_{i j}^{\prime}\right\rangle
$$

with the definition of turbulence dissipation rate, we could obtain the fluctuating enstrophy

$$
\mathbf{\Omega}^{\prime}=\frac{1}{2} \omega_{i}^{\prime} \omega_{i}^{\prime}=e_{i j}^{\prime} e_{i j}^{\prime}=\frac{\varepsilon}{2 v}
$$

the sum of these two terms thus can be calculated and the enstrophy in the passage can be obtained.

Based on the enstrophy equations, the enstrophy dissipation rate can also be proposed analogous to the kinetic-energy dissipation rate.

$$
\Phi_{\omega}=\mu \nabla \omega_{z}=\mu\left[\left(\frac{\partial^{2} v}{\partial x^{2}}-\frac{\partial^{2} u}{\partial y \partial x}\right) \vec{i}+\left(\frac{\partial^{2} v}{\partial x \partial y}-\frac{\partial^{2} u}{\partial y^{2}}\right) \vec{j}+\left(\frac{\partial^{2} v}{\partial x \partial z}-\frac{\partial^{2} u}{\partial y \partial z}\right) \vec{k}\right]
$$


The vorticity is a three-dimensional vector, but in the impeller passage, the streamwise vortex is the main object. Hence, the streamwise vorticity, which is the $\omega_{z}$ was considered when calculating the enstrophy dissipation rate.

\section{Preliminary Design of a S-CO 2 Axial Turbine}

To investigate the turbine internal flow, a S-CO $\mathrm{CO}_{2}$ turbine is designed as the first step. The nominal thermodynamic conditions of the designed turbine are summarized in Table 1. In this paper, the axial configuration was adopted since the authors believed that the axial turbine is more appropriate for small-scale $\mathrm{S}-\mathrm{CO}_{2}$ systems. For power outputs below a megawatt, small size and high operating pressure of $\mathrm{S}-\mathrm{CO}_{2}$ turbine lead to a high rotational speed. The high rotational speed brings about many difficulties on the stable and efficient operation, and the large absolute pressure difference leads to large leakage flow losses within the turbines [35]. Compared with the radial turbine, the axial structure could reduce either turbine rotational speed and stage pressure ratio by adding expansion stages. And partial admission could also be utilized with axial configuration if the turbine was operated at low power output conditions.

Table 1. Thermodynamic parameters of $\mathrm{S}-\mathrm{CO}_{2}$ cycle.

\begin{tabular}{ccc}
\hline Parameters & Unit & Value \\
\hline Turbine inlet total pressure & $\mathrm{MPa}$ & 12 \\
Turbine inlet temperature & $\mathrm{K}$ & 493.15 \\
Turbine total-to-static pressure ratio & - & 1.875 \\
Rotational speed & $\mathrm{rpm}$ & 40,000 \\
Mass flow rate & $\mathrm{kg} / \mathrm{s}$ & 5.08 \\
Power & $\mathrm{kW}$ & 160 \\
\hline
\end{tabular}

The fundamental design methodology of the axial turbine has been developed and discussed in books and scientific papers. Since there lacks a suitable design method for the $\mathrm{S}-\mathrm{CO}_{2}$ turbine, this paper still follows the introduced turbine design methodology. At the beginning of the design, non-dimensional parameters including degree of reaction, flow coefficient, and loading coefficient are used to help to select a geometry optimizing efficiency using a limited set of variables. The degree of reaction indicates the distribution of the isentropic enthalpy drop in the turbine. Different reaction degree values correspond to different velocity distribution and pressure distribution. Due to the large pressure drop through the $\mathrm{S}-\mathrm{CO}_{2}$ turbine, the axial force is largely related to the pressure distribution and it could influence the availability of the bearings. Zero degree of reaction is chosen considering the bearings and impeller exit velocity. The flow coefficient has to be 0.5 if zero degree of reaction and free vortex were adopted, according to the Ref. [44]. Other geometrical parameters such as the blade angles are further determined based on these non-dimensional parameters and one-dimensional analysis. The final specifications of the designed turbine can be found in Table 2, the 3D geometric model of the S- $\mathrm{CO}_{2}$ axial turbine is presented in Figure 1. It can be seen that the designed turbine has the geometrical features as discussed in the previous. Although the turbine output power is $160 \mathrm{~kW}$, the turbine has only a $4 \mathrm{~mm}$ blade span and a $24 \mathrm{~mm}$ hub radius. Small size and large power lead to a small aspect ratio and a large hub-to-tip ratio of the blades, which is 0.37 and 0.86 respectively.

To further analyze how blade geometrical features influence on the turbine internal flow, a similar S-CO $\mathrm{CO}_{2}$ axial turbine with a larger aspect ratio and a smaller hub-to-tip ratio was developed and investigated as a comparison. To distinguish these two turbines, the originally designed turbine is referred to as "Designed Turbine (D Turbine)" in the following, and the turbine developed for comparison is referred to as "Compared Turbine (C Turbine)" in the following. All the operational and geometrical parameters of the C Turbine are the same as D Turbine except the blade span. C Turbine has a blade span of $8 \mathrm{~mm}$, which is twice as much as that of D Turbine. As a result, the blade aspect ratio of the 
C Turbine is 0.75 , which is larger than that of the $\mathrm{D}$ Turbine. The hub-to-tip ratio of the $\mathrm{C}$ Turbine is 0.75 , which is smaller than that of the $\mathrm{D}$ Turbine. The tip clearance ratio remains $2.5 \%$ for two turbines to avoid the influence of tip leakage flow. The schematic diagrams of D Turbine and C Turbine are presented in the Figure 2.

Table 2. Specifications of the designed $\mathrm{S}-\mathrm{CO}_{2}$ turbine impellers.

\begin{tabular}{ccc}
\hline Parameters & Unit & Value \\
\hline Reynolds number based on $U_{3}$ and $C$ & - & $1.2 \times 10^{7}$ \\
Flow coefficient & - & 0.5 \\
Hub radius $\left(R_{h u b}\right)$ & $\mathrm{mm}$ & 24 \\
Blade span $(h)$ & $\mathrm{mm}$ & 4 \\
Chord $(C)$ & $\mathrm{mm}$ & 10.72 \\
Axial chord $\left(C_{x}\right)$ & $\mathrm{mm}$ & 10.68 \\
Pitch $(s)$ & $\mathrm{mm}$ & 5.27 \\
Tip gap height $(\tau)$ & $\mathrm{mm}$ & 0.1 \\
Aspect ratio $\left(h / C_{x}\right)$ & - & 0.37 \\
Hub-to-tip ratio $\left(R_{h u b} / R_{\text {Tip }}\right)$ & - & 0.86 \\
Tip clearance ratio $(\tau / h)$ & $\%$ & 2.5 \\
\hline
\end{tabular}

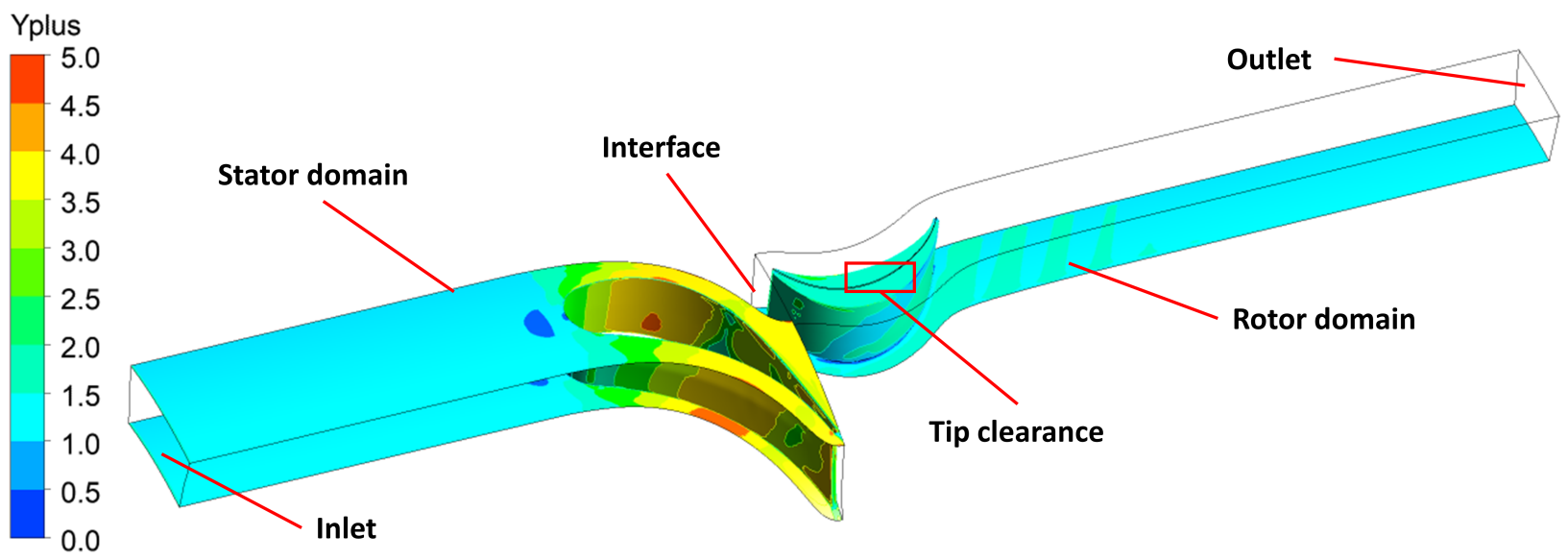

(a)

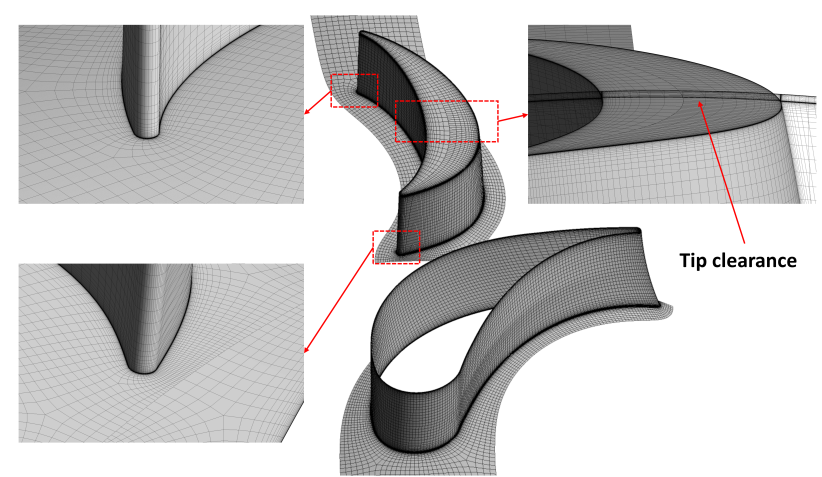

(b)

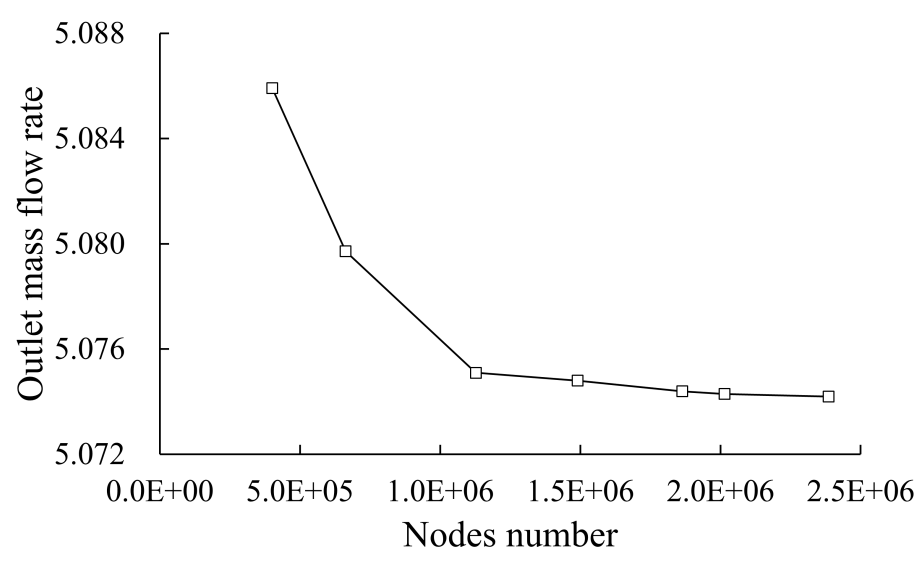

(c)

Figure 1. Single channel fluid domain mesh and $y+$ value distribution in the designed turbine. (a) Domain $y+$ value distribution; (b) Domain mesh; (c) Mesh independence. 


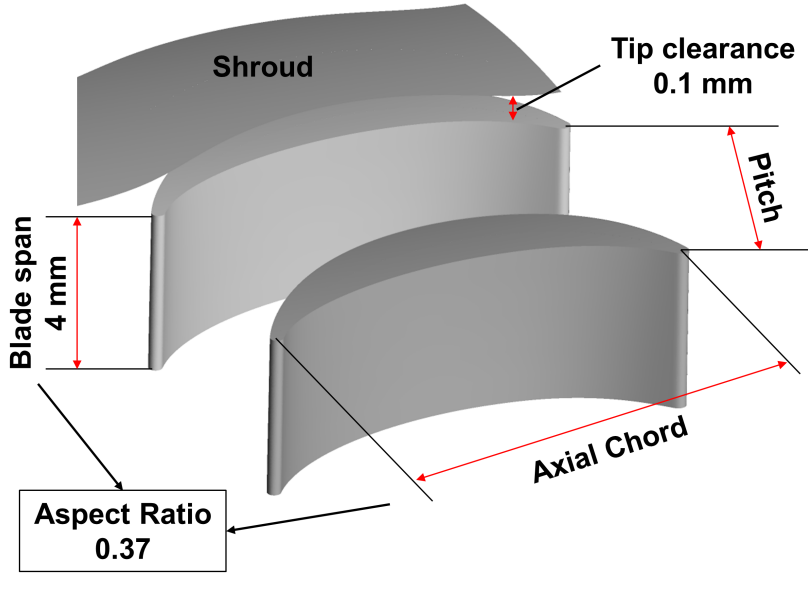

(a)

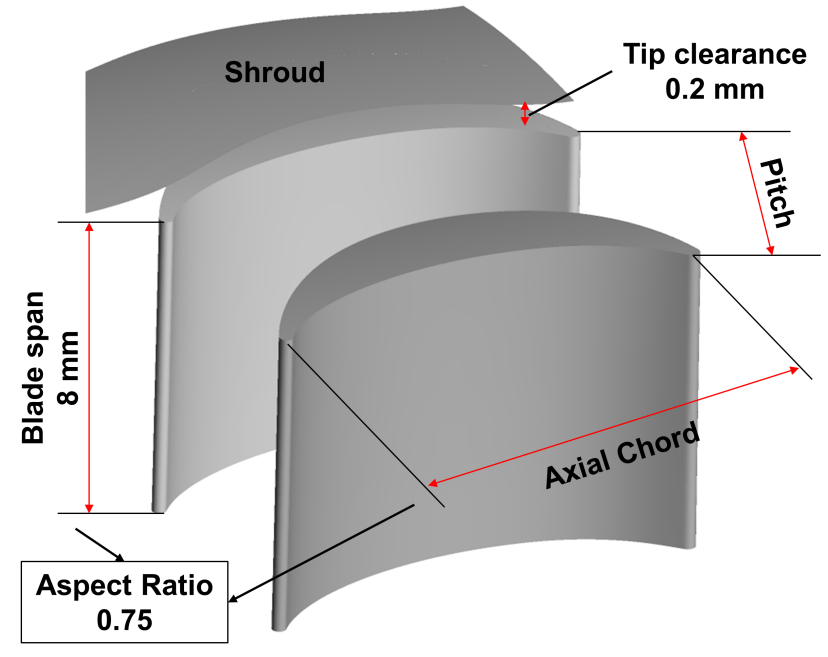

(b)

Figure 2. Schematic diagrams of impellers of two turbines. (a) D Turbine; (b) C Turbine.

\section{Numerical Methods}

The operating pressure of the designed $\mathrm{S}-\mathrm{CO}_{2}$ turbines is $12 \mathrm{MPa}$, accurate captures of $\mathrm{S}-\mathrm{CO}_{2}$ flow structure in the turbines through experimental methods thus become very difficult and time-consuming. Numerical simulations on the designed turbine are used in this paper to conduct investigations on turbine internal flow characteristics. Viscous turbulent computational fluid dynamics (CFD) methods were carried out at the turbine nominal condition with the mature commercial solver, ANSYS CFX 19.2. The discretization for the spatial terms in the governing equations was the second-order implicit upwind difference scheme. The time term was discretized by the second-order backward difference Euler scheme.

\subsection{Turbulence Model}

Due to the importance of the secondary flows within $\mathrm{S}-\mathrm{CO}_{2}$ impeller passage and high Reynolds numbers, ANSYS CFX solver guide specifies that the two-equation k-omega based Shear-Stress-Transport (SST) model by Menter [45] instead of the widely-used kepsilon model are preferred as the turbulent model [46]. The widely used solution for three dimensional turbulent flows is the Reynolds Averaged Navier-Stokes (RANS) equations.

\subsection{Computational Model and Mesh Generation}

Since the blades are periodically distributed in the circumferential direction, the calculations were conducted with a single-channel computational model. The software TurboGrid was used to generate the structured mesh as shown in Figure 1b. Mesh refinements were required to accurately predict the flow separation with the selected turbulence model, the first layer within the mesh should be sized to retain y+ close to 1 . For representative inlet conditions, density is two orders of magnitude greater for $\mathrm{S}-\mathrm{CO}_{2}$ than air. This leads to a first layer height in $\mathrm{S}-\mathrm{CO}_{2}$ turbine mesh 2 orders of magnitude smaller than for gas turbines with the same $y+$. As a result, a low $y+$ value and low aspect ratio in the mesh are difficult to be guaranteed at the same time, unless the mesh was generated with a very large number of nodes. In this paper, the final mesh had an average $y+$ close to 1.5 in the first layer, except in regions near the nozzle blade hub, where $y+$ can reach values as high as 5. Figure 1 a reveals the computational model and its $y+$ value distribution. The mesh independence verification was assessed based on turbine outlet mass flow using steady-state simulations, results can be seen in Figure 1c. For the designed Turbine, final mesh was created with a total grid number of 2,015,613 nodes, 886,895 for the nozzle, $1,128,718$ for the impeller. 


\subsection{Fluid Properties}

Unlike in the $\mathrm{S}-\mathrm{CO}_{2}$ compressors, the bulk fluid in the $\mathrm{S}-\mathrm{CO}_{2}$ turbines has a high compressibility factor close to 0.9 during expansion. Therefore, no rapid rate of property change and a non-equilibrium phase change process is expected in the turbine. The NIST Span and Wagner (S-W) equation of state model, established by Reference Fluid Thermodynamic and Transport Properties Database [47], was utilized and incorporated in the CFD solver in the form of lookup tables. The Real Gas Property (RGP) lookup table was sized at $1500 \times 1300$, the pressure ranged from $2 \mathrm{MPa}$ to $17 \mathrm{MPa}$ with $1 \mathrm{kPa}$ as an increment, the temperature ranged from $250 \mathrm{~K}$ to $900 \mathrm{~K}$ with $0.5 \mathrm{~K}$ as an increment.

\subsection{Boundary Conditions and Solution Settings}

All simulations were carried out at design point with the operating conditions summarized in Table 1 unless otherwise noted. Boundary conditions were set as total conditions at the inlet and static pressure in the stationary frame at the exit of the domain. The inlet flow to the nozzle is modeled with a flow angle of $37^{\circ}$, this flow angle was obtained from another simulation with full-channel nozzles, impellers, and a volute. Inlet flow was assumed to be fully turbulent, and 5\% turbulence intensity was modeled. For steady-state simulations, the mixing plane interface based on stage average total pressure was adopted in this single-channel model. The impeller blade was modeled with a space of $0.4 \mathrm{~mm}$ between the start of the rotating domain and the blade leading edge. An extension of five times the impeller blade axial chord length was added to the impeller mesh to minimize the influence of boundary conditions. Tip clearance was modeled with a gap of $0.1 \mathrm{~mm}$ between the impeller blade tip surface and shroud surface. The shroud surface is modeled as nonrotating. No-slip, adiabatic wall boundary conditions were applied on the blade and endwall surface. Periodic boundary conditions were applied as only one blade passage for both the nozzle and the impeller is modeled.

Solutions were deemed to be converged when RMS residuals for mass, momentum, and turbulence had reduced by at least 7 orders of magnitude. Otherwise, two criteria were utilized to demonstrate the computation convergence, namely less than $1 \%$ difference between inlet and outlet mass flow rate, less than $1 \%$ fluctuation in pressure and temperature.

\subsection{Experimental Validations}

Validation of the numerical method is a necessary part of the simulations to ensure the accuracy of the simulation results. As the experimental data for the $\mathrm{S}-\mathrm{CO}_{2}$ turbine is scarce in the open literature, the D turbine is thus manufactured and tested, the introduction of the experimental apparatus and the concrete experimental process can be found in Refs. [48,49]. Due to the low power of the heat source, the manufactured turbine adopted a partial admission nozzle to reduce the mass flow rate.

Since only specific data could be collected, the mass flow rate and the turbine isentropic total-to-static efficiency were used to validated the simulation results. The isentropic totalto-static efficiency is defined in Equation (14).

$$
\eta_{T S}=\frac{P_{\text {output }}}{\dot{m}\left(h_{01}-h_{4}\right)} \cdot \frac{1}{\eta_{m} \eta_{e l}}
$$

The $\eta_{m}$ represents the mechanical efficiency and the $\eta_{e l}$ represents the electrical efficiency. The values were provided by the cooperative manufacturer of the prototype. The $\eta_{m}$ is 0.94 and the $\eta_{e l}$ is calculated with Equation (15). These two efficiency values are only used when calculating the experimental data.

$$
\eta_{e l}=0.0000025275 * n+0.0157347619
$$

The simulated and experimental results are displayed in Figure 3. The simulated results are presented with lines and the experimental results are presented with symbols. Due to the rotational speed of the $\mathrm{S}-\mathrm{CO}_{2}$ turbine was fluctuating during the experiments, the symbols that indicates the experimental results of turbine rotational speed between 
$31,000 \mathrm{rpm}$ and 36,000 rpm cover a larger area in the figure. But it can be still seen that the simulated results matches well with the experimental results. The numerical models used in this paper thus is believed to be feasible and the simulation results of $\mathrm{S}-\mathrm{CO}_{2}$ turbine are credible.

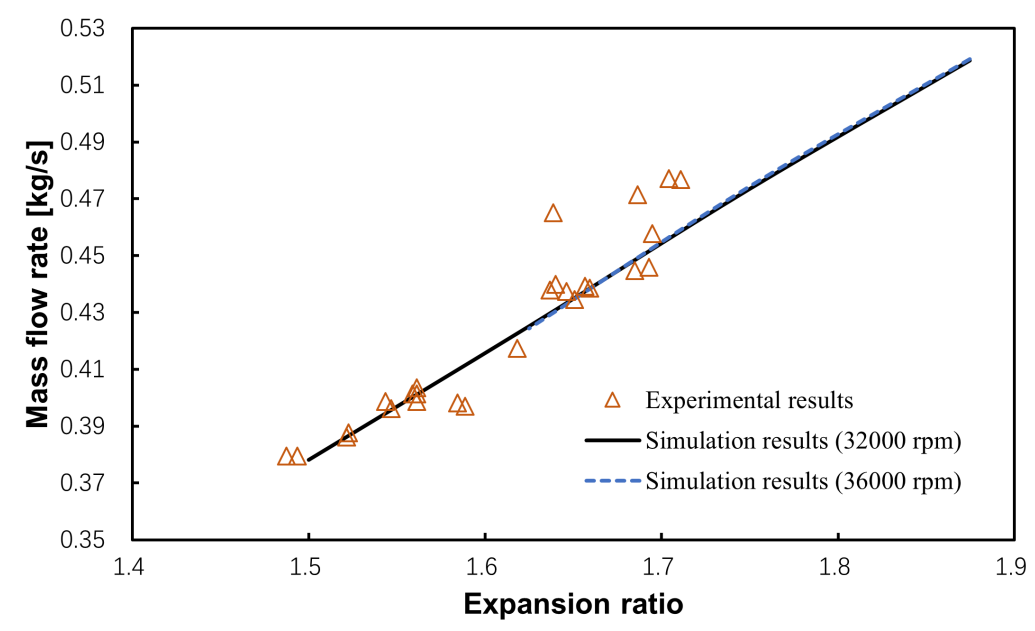

(a)

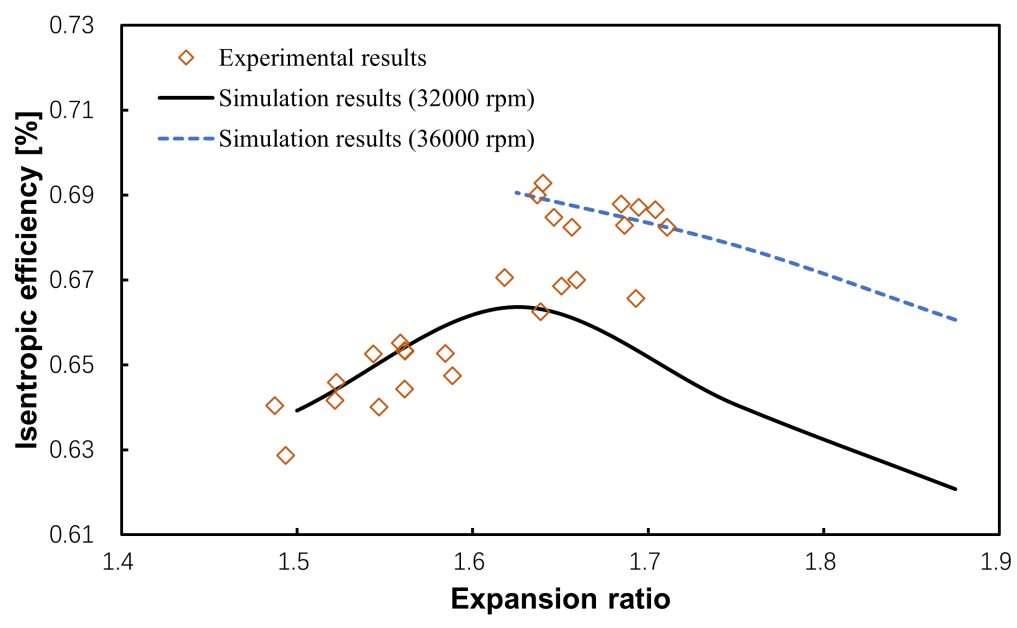

(b)

Figure 3. Comparison of simulations and experiments. (a) Mass flow rate; (b) Isentropic total-tostatic efficiency.

\section{Results and Discussions}

The detailed investigations on the flow field in the turbines are presented in this section. All the flow fields are extracted from three-dimensional steady-state simulation results. However, the flow patterns and the energy transfer process are more easily understood from the point of view of a two-dimensional but unsteady flow. Hence, an analogous translation along the streamwise direction to the moving time is proposed. More specifically, the flow status in different axial locations can be represented by the unsteady flow at different times. It implies that the evolution of the cross-plane flow structure (including vortices strength and position) at different streamwise locations is similar to that at different times, when viewed from a moving reference frame. All the discussion and analysis in the current paper are carried out based on this analogy. Note that in descriptions of the flow field, the generic term "Secondary Flow" is used to represent any deviation from the streamwise flow direction within the impeller passage, and should not be misinterpreted as the term "Passage Vortex". 


\subsection{Overall Secondary Flow Features in the Passage}

The overall flow visualization results in the D Turbine are presented in Figure 4. The D Turbine is the designed $\mathrm{S}-\mathrm{CO}_{2}$ axial turbine with a low aspect ratio and large hub-to-tip ratio. A detailed flow structure can be seen in Figure $4 \mathrm{a}$ with fluid streamlines coloring with the streamwise vorticity. The positive streamwise vorticity in the figure represents the vorticity that has the same direction as the mainstream flow, and the negative value represents the vorticity that has the opposite direction as mainstream flow. Through streamlines distribution, the tip endwall flow, hub endwall flow, and the tip leakage flow in the passage can be identified.

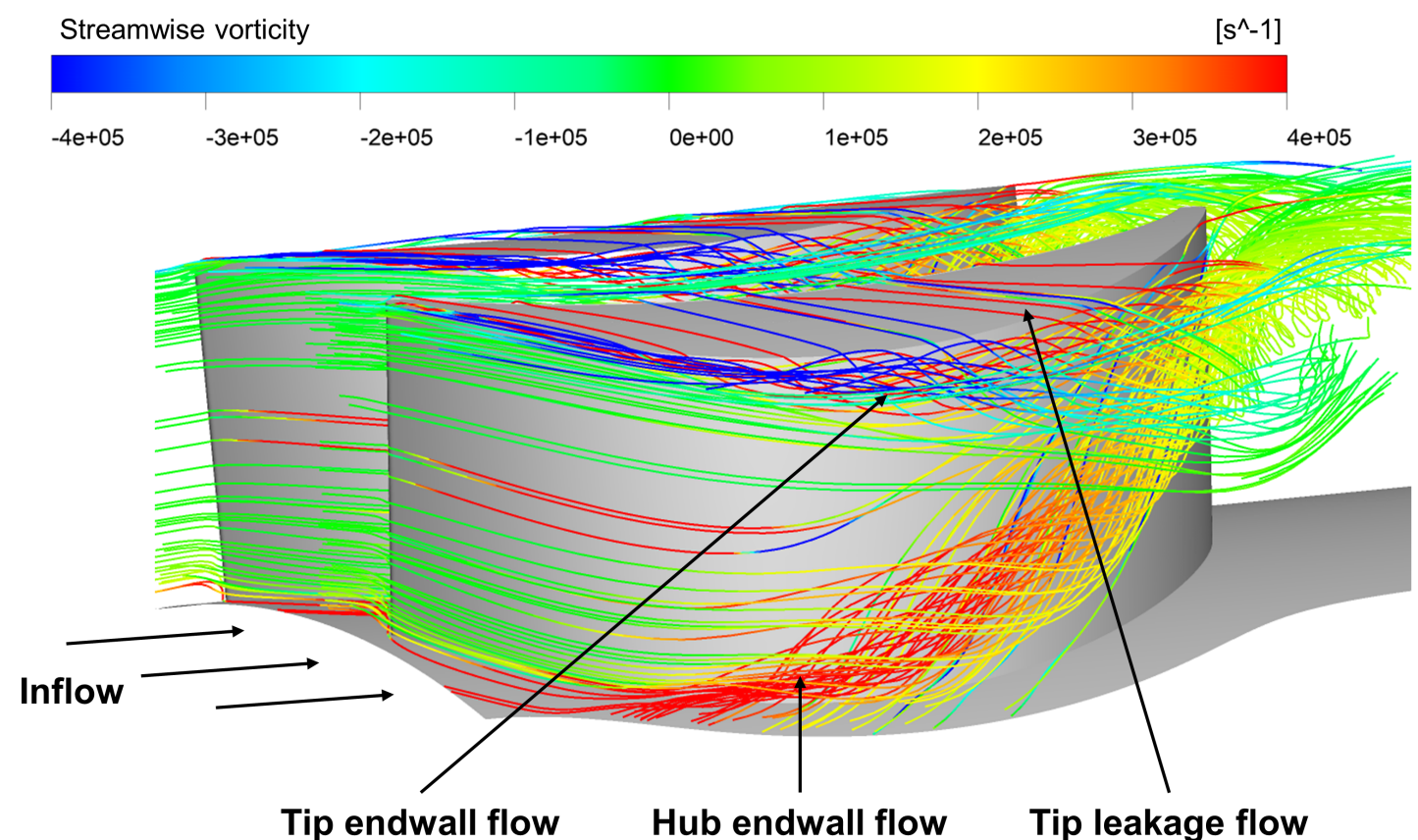

(a)
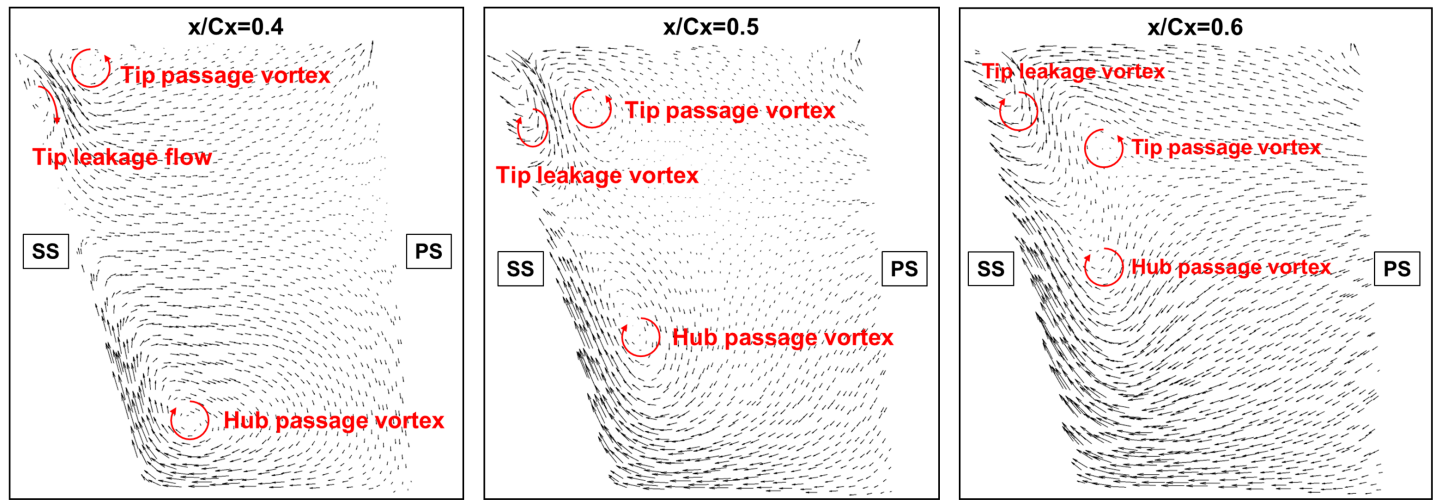

(b)

Figure 4. Secondary flow distribution in the impeller passage of D Turbine. (a) Streamlines distirbution with streamwise vorticity; (b) Tangiental velocity vector projected on the transverse planes at different axial chord locations.

The hub secondary flow is generated near the suction side and moves towards the blade tip along the blade, main flow in the middle section and near-wall flow next to the blade suction surface is entrained to enhance the flow strength of the hub secondary flow. While in the shroud section, the secondary flow structure is more complex. The passage flow is rolled up as a result of the shear-across leakage jet near the blade tip and leading edge. This roll-up formed a secondary flow and downstream the inner core of 
the leakage vortex, which is one source of the increase in vorticity in the shroud section. At downstream, the leakage vortex entrains more leakage jet and increases the size of the vortex. However, not all the passage flow is entangled in the inner core of the leakage vortex. The blue streamlines in the figure show that much of the passage flow is forced by the side of the vortex core instead of wrapping around it. Different from the secondary flow rolled by the tip leakage flow, the tip endwall flow is generated more upstream, at the location of around 50\% axial chord. The color on the streamlines indicates that the tip endwall flow and the tip leakage flow have the opposite vorticity direction, which is used to distinguish these two flows. The tip leakage flow seems stronger than the tip endwall flow downstream as the blue streamlines are pushed away from the blade with a decrease in the vorticity. At the location of $90 \%$ axial chord, all of these three flows intertwine with each other and leave the impeller passage together.

The tangential velocity vector projected on the transverse planes (or called the S3plane) at different axial chord locations, as is displayed in Figure $4 b$, is used to identify the detailed vortices distribution. In the figure, both the tip passage vortex and the hub passage vortex are formed at the location of $40 \%$ axial chord, while the tip leakage flow is still weak and squeezed by the tip passage vortex, the tip leakage vortex is not formed and is unclear. Downstream at the location of $50 \%$ axial chord, the tip passage vortex and the hub passage vortex are moving in the spanwise direction along the blade, and the tip leakage flow begins to roll up. Compared with the tip passage vortex, the hub passage vortex moves faster. The hub passage vortex reaches the mid-span when the tip passage vortex is still at around 0.75 span at the location of $60 \%$ axial chord. As the tip passage vortex moves away from the blade suction surface, the interaction between the tip passage vortex and tip leakage flow becomes smaller, the tip leakage vortex seems to form itself.

Considering the big vortex at the impeller outlet shown in Figure $4 \mathrm{a}$ and the positions of the tip leakage vortex, the tip passage vortex, and the hub passage vortex shown in Figure $4 \mathrm{~b}$, it is thus suggested that an interaction between these three vortices occurs in the passage. Therefore, Q-criterion is used to demonstrate the formation and development process of the vortices.

Figure 5 shows the streamwise Q-criterion distribution at different axial chord locations. A full formation process of vortices including the passage vortices and the tip leakage vortex can be seen through Figure 5a, and the detailed overviews of the vortex structure on the different $\mathrm{S} 3$ planes are provided in the Figure $5 \mathrm{~b}$. In the figure, the vortex moving tracks analyzed previously can be confirmed. The passage vortices are formed in the streamwise first half of the passage. At the location of $20 \%$ to $30 \%$ axial chord, a hub passage vortex with a large size and an oblate tip passage vortex with small size are presented. The authors speculate that the large centrifugal force is the main reason for this phenomenon. In the $\mathrm{S}-\mathrm{CO}_{2}$ turbine, the working fluid withstands a large centrifugal force in the passage due to the high density of supercritical carbon dioxide and the high rotational speed of the turbine. The structure of the hub passage vortex is elongated and thrown towards the outer casing under the action of this radial centrifugal force, while the tip passage vortex is squeezed and stays in the shroud section. With a large size of hub passage vortex, more main flows are entrained around the vortex and it moves quickly from the hub section to the mid-span section, as can be seen in the planes at $20 \%, 40 \%$, and $60 \%$ axial chord. At the same locations, the tip passage vortex is formed and wrestling with the tip leakage flow and its associated vortex. In the downstream locations, the large part of the tip leakage jet and entrainment of the main flow make the tip leakage vortex gradually stronger than the tip passage vortex. Then the tip passage vortex is pushed away by the tip leakage vortex as shown in the Q-criterion contour at $80 \%$ axial chord. This kind of shear interaction between the tip leakage vortex and the tip passage vortex has been investigated in the gas turbines. The difference is that the tip leakage flow becomes dominant in the shroud section in this $\mathrm{S}-\mathrm{CO}_{2}$ turbine, though the tip clearance is only $0.1 \mathrm{~mm}(2.5 \%$ tip clearance ratio) in this case. 


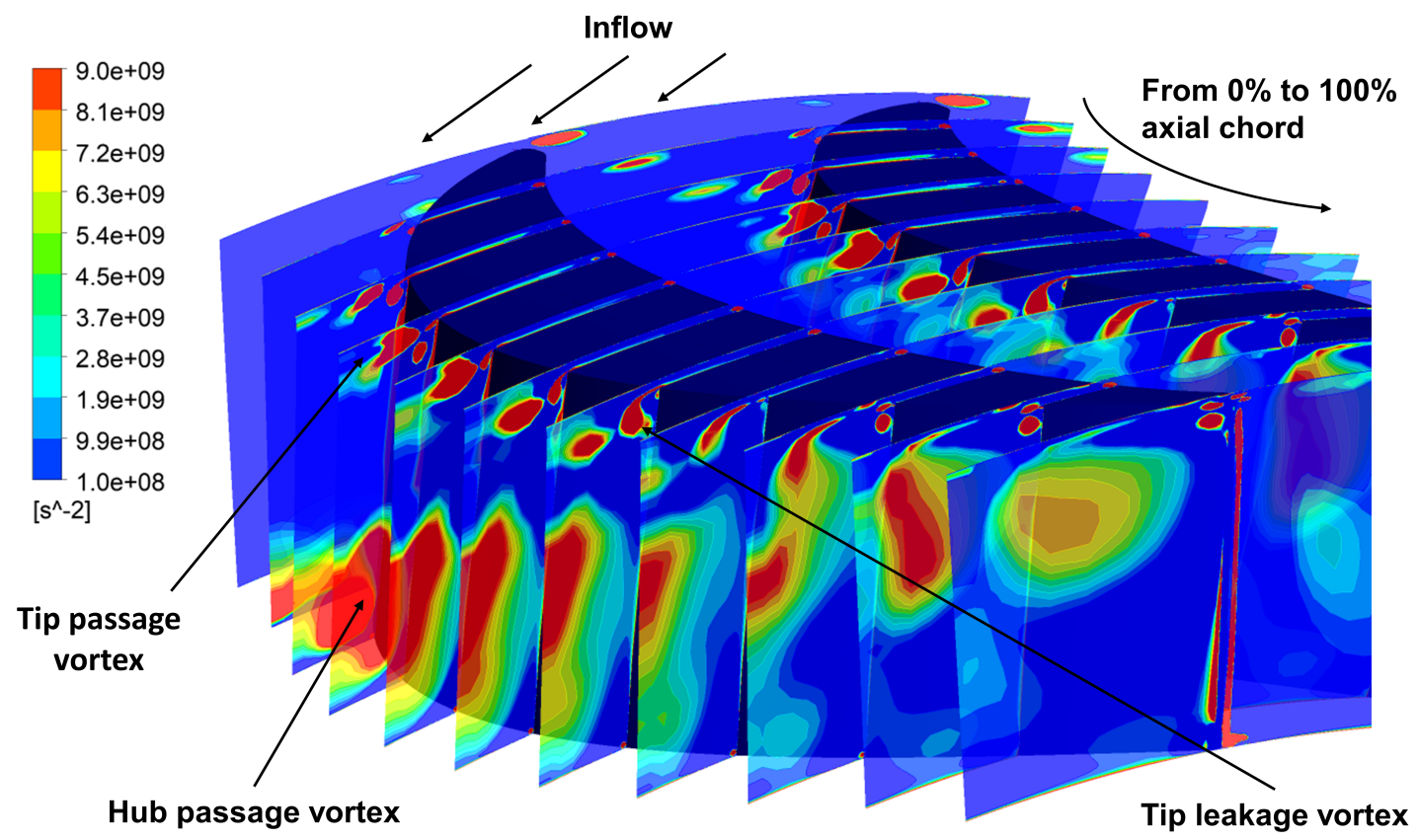

(a)
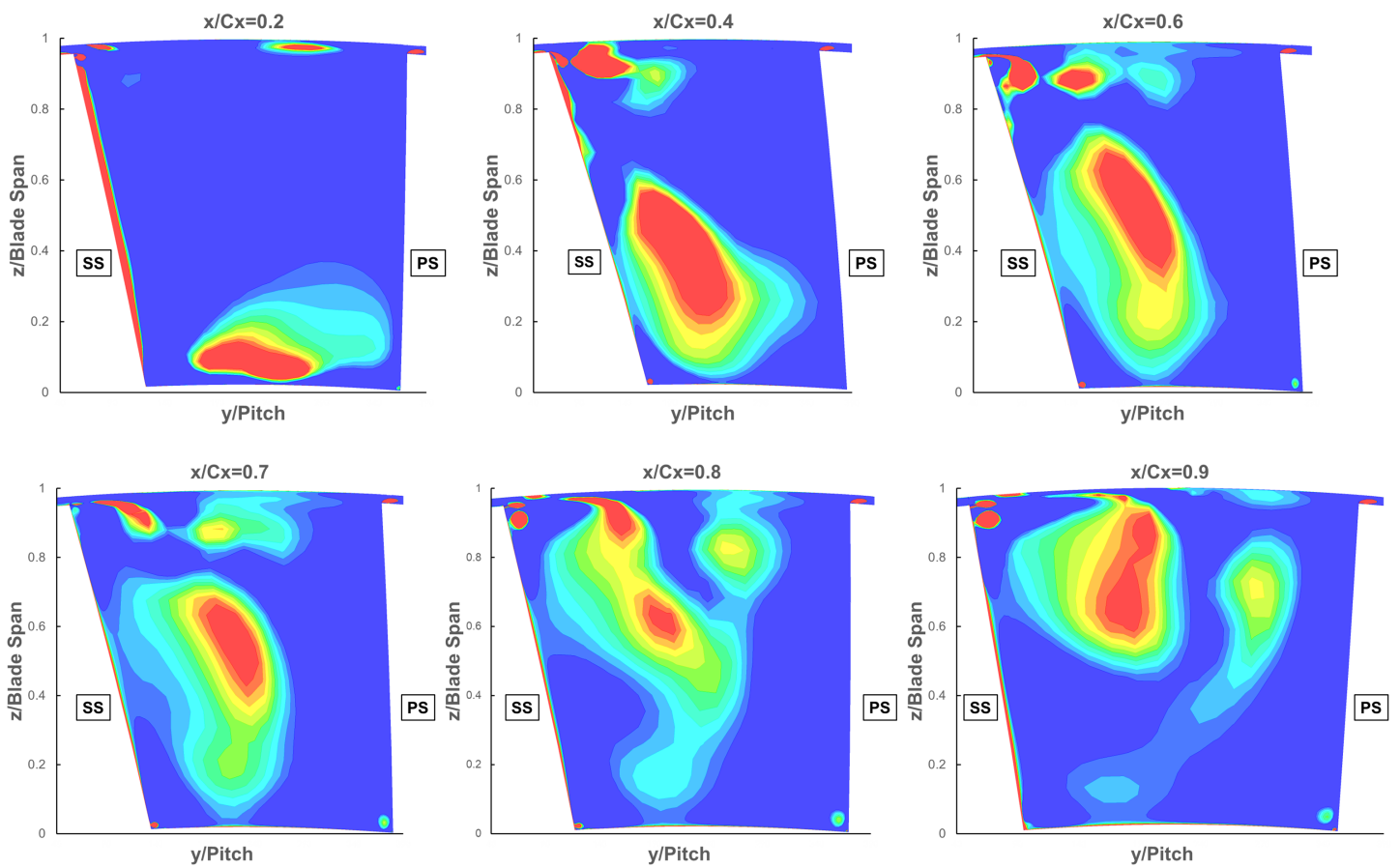

(b)

Figure 5. The Q-criterion distribution in the D turbine impeller passage. (a) Overall Q-criterion distribution; (b) Q-criterion projected on the transverse planes at different axial chord locations.

However, the moving tracks of the passage vortices shown in the Figure $5 \mathrm{~b}$ seem different in the rear part of passage from that in the gas turbine impellers. Figure $5 b$ indicates that the tip passage vortex is detached and further pushed away from the blade at $80 \%$ axial chord when the tip leakage vortex entangles itself with the hub passage vortex. As a comparison, Figure 6 gives the vorticity distribution in a normal gas turbine rotor cascade. It can be seen that in the gas turbine the hub passage vortex and the tip passage vortex touch with each other in the mid-span section near the blade trailing edge and the tip leakage vortex stays in the shroud section. And in the $\mathrm{S}-\mathrm{CO}_{2}$ turbine, the tip leakage 
vortex and the hub passage vortex have a contact. Without an obstruction of the tip passage vortex, the fast-moving hub passage vortex moves upwards and touches the enlarged tip leakage vortex in the shroud section. Closer inspection of Figure $4 \mathrm{a}$ shows that the hub passage vortex does not enter the innermost core of the leakage vortex, instead, it entrains around the leakage vortex. The final generated large vortex would be referred to as "Merged vortex". The size of this merged vortex keeps increasing with the entrainment of the hub passage vortex. Although the merged vortex is still close to the blade, its inner core, which is the tip leakage vortex, already detaches from the suction surface of the blade. As the $\mathrm{S}-\mathrm{CO}_{2}$ turbine has a strong tip leakage flow, more fluid in the passage is entrained by the tip leakage jet and the tip leakage vortex. Therefore, the vorticity convection from the fluid near the outer-casing downstream is less influential to the structure of the tip passage vortex.

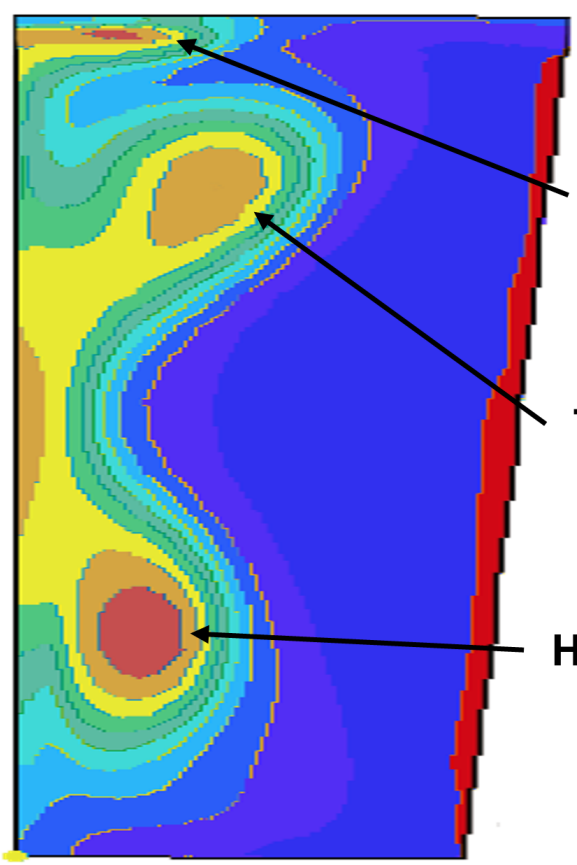

$x / C x=0.7$

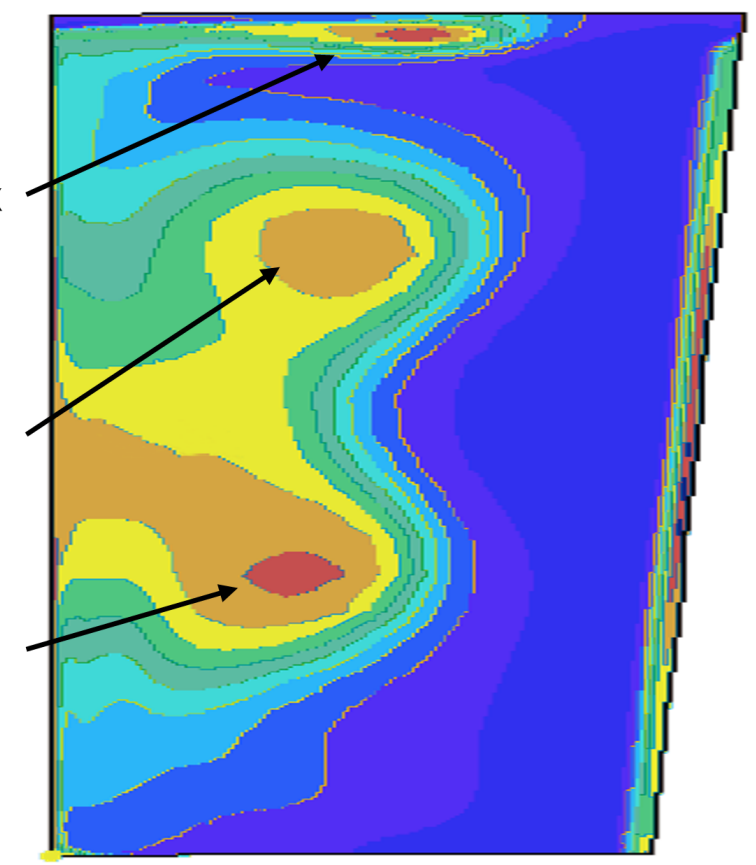

$x / C x=0.9$

Figure 6. Vorticity distribution in the gas turbine rotor cascade.

Same vortex interaction is not expected in traditional axial turbines, as shown in Figure 6, which displays the vortex flow patterns in a normal gas turbine. More concretely, an intuitive comparison of flow features is given in Figure 7. The D Turbine is the designed $\mathrm{S}-\mathrm{CO}_{2}$ turbine, and the $\mathrm{C}$ Turbine is a turbine with a large blade aspect ratio and small blade hub-to-tip ratio. The geometrical features of the $C$ Turbine are similar to those of gas turbines. In the figure, the blue ribbon lines are streamlines in the shroud section, which indicates the tip flow, and the red ribbon streamlines indicate the hub flow. It can be found that the basic structure of flow patterns are similar in the two turbines, while the structure of the secondary flows near the trailing edge is different in the D Turbine from that in the C Turbine and the gas turbine (Figure 6). The large tip clearance ratio makes the tip leakage flows have a large effect on the main flow and influences more area in the passage, both in the C Turbine and D Turbine, while the hub endwall flow in the D Turbine moves towards the outer casing quickly and join the tip flows in the tip section. At the impeller outlet, the hub flows and the tip flows are separated structures in the C Turbine and the same flows are twisted together in the D Turbine. It identifies that the tip leakage vortex and the hub passage vortex have interacted with each other in the D Turbine. 


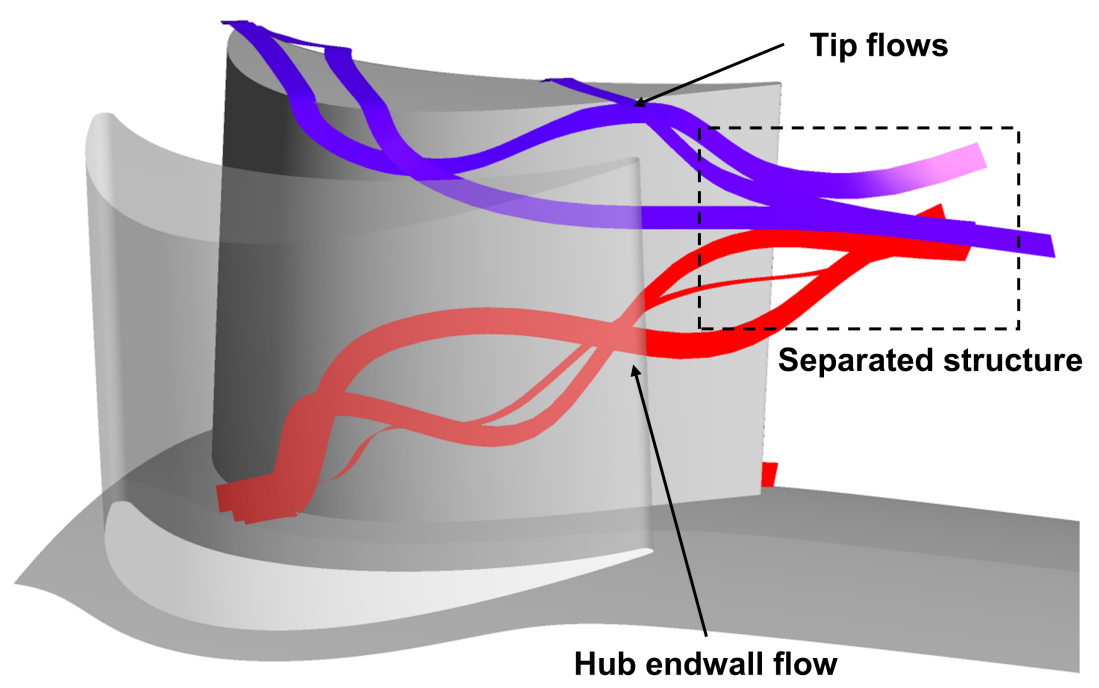

(a)

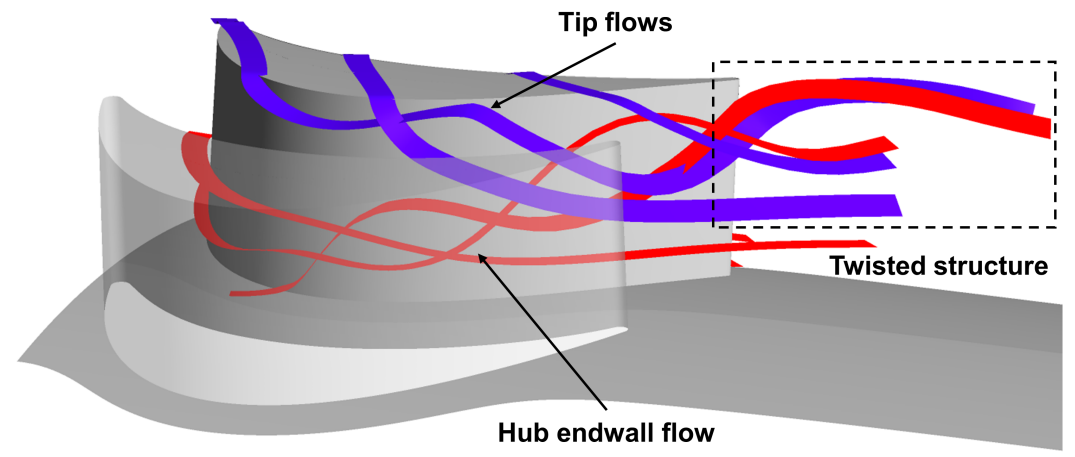

(b)

Figure 7. The flow structure described in the two $\mathrm{S}-\mathrm{CO}_{2}$ turbine impeller passages. (a) Flow patterns in the C Turbine (Compared Turbine); (b) Flow patterns in the D Turbine (Designed Turbine).

\subsection{Investigation on Vortex Interaction of Tip Leakage Vortex and Hub Passage Vortex}

Although the interaction of the tip leakage vortex and tip passage vortex is a complex process investigated in the literature, the interaction of the tip leakage vortex and the hub passage vortex is an unanticipated flow structure and was not discussed in the previous study. As is shown in Figure 6, the normal vortex structure in the gas turbine is that the tip passage vortex and the hub passage vortex meet each other in the mid-span section, while the vortex patterns become different in the studied $\mathrm{S}-\mathrm{CO}_{2}$ turbine. The development mechanism of vortex interaction is thus investigated in this section.

To further analyze the detailed structure of vortices, an improved vortex tracking parameter, $Q_{\text {improve }}$, is proposed in the present paper based on the Q-criterion. $Q_{\text {improve }}$ can either detect the vortex in the flow field or present the rotational direction of the vortex. Its definition is revealed in Equation (16).

$$
Q_{\text {improve }}=\frac{\omega}{|\omega|} \times \frac{Q+|Q|}{2}
$$

Figure 8a shows the distribution of $Q_{\text {improve }}$ value on the transverse plane at $60 \%, 80 \%$ and $90 \%$ axial chord. In the figure, the red region represents the clockwise vortex in the passage when it is observed along the mainstream, and it is referred to as the "Positive Vortex" in the following. The blue region represents the counterclockwise vortex, which is referred to as the "Negative Vortex" in the following. According to their formation 
processes, the tip leakage vortex and the hub passage vortex are classified as the positive vortices, the tip passage vortex is classified as the negative vortex.

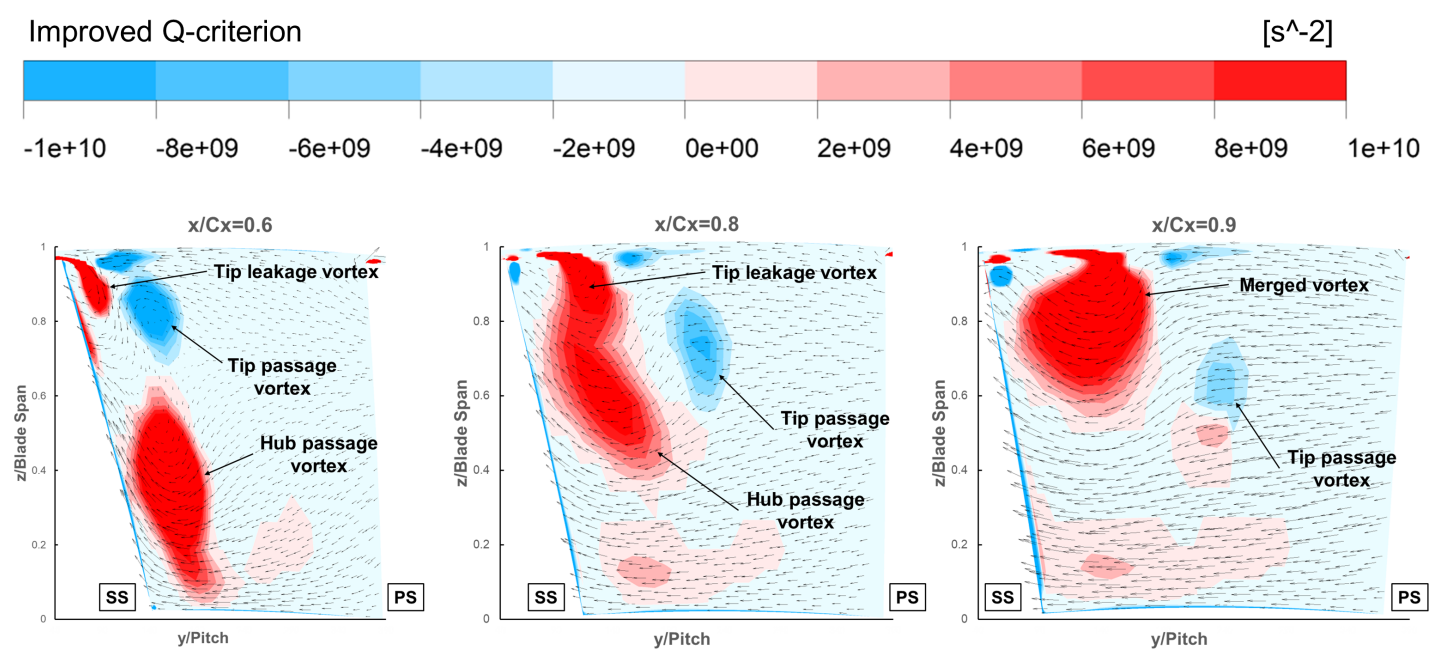

(a)
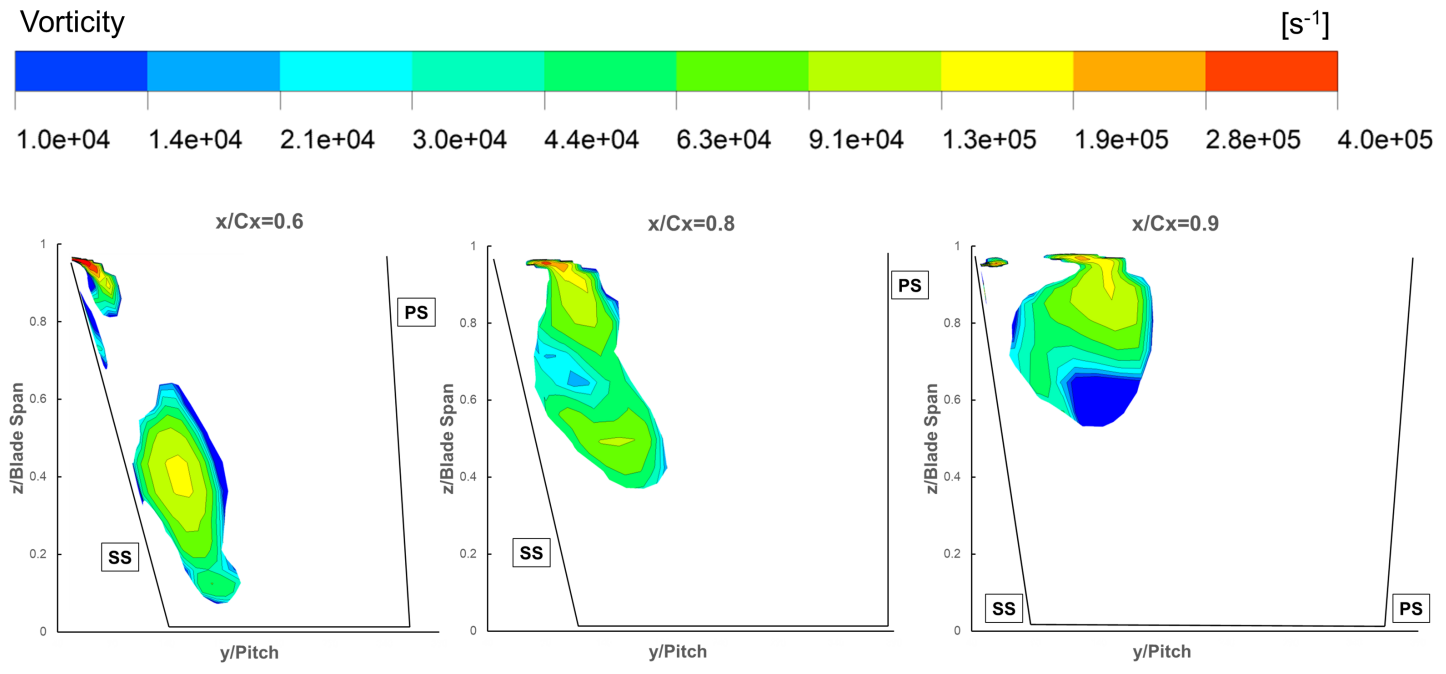

(b)

Figure 8. Vortex interaction process in the D turbine impeller passage. (a) Improved Q criterion distribution in the passage; (b) Vorticity contour in the positive vortices.

From the figure, we can see that tip leakage vortex, tip passage vortex, and hub passage vortex can be recognized in the figure at $60 \%$ axial chord. While downstream in the S3 plane at $80 \%$ axial chord, the hub passage vortex moves towards the tip leakage vortex and these two vortices start to merge. Compared with the merged vortex, the tip passage vortex is pushed away, which has a smaller size and a lower vortex strength. At the location of $90 \%$, the tip leakage vortex and the hub passage vortex finally become one vortex, and the tip passage vortex is almost dissipated. The trajectory of the vortices displays that the merged vortex is developed based on the tip leakage vortex. The hub passage vortex moves into the tip leakage vortex and causes the merge process.

Knowing the vortices' positions and their direction, investigations on the detailed vortices merge process are carried out by analyzing the vorticity distribution. Figure $8 b$ gives the vorticity contour in the positive vortices which can visually present the structural changes of the vortices when the interaction occurs. In the beginning, the tip leakage vortex is formed in the shroud section with the high vorticity concentrated in the upper part, and 
the hub passage vortex moves quickly towards it. Downstream at the $80 \%$ axial chord, the enlarged tip leakage vortex is instrumental in bringing the hub passage vortex into contact but does not itself display any strong deformation, while the hub passage vortex is greatly compressed when it touches the tip leakage vortex. The deformation occurs as a result of the intense collision of vortical particles at the interface of two vortices. The vortex is a helical structure with the fluid warping around the innermost vortex core. So the adjacent vortices with the same rotational directions have the opposite flow direction on the interface. Both the tip leakage vortex and the hub passage vortex are positive vortices, When two vortices touch with each other, the rotating fluid particles on the periphery of the vortices would meet, collide, and decelerate. Thus, the fluid rotating velocity and the streamwise vorticity of the vortex are decreased, the vortex strength is weakened, and the vortex size is reduced. Compared with the hub passage vortex, the tip leakage vortex has larger vorticity and stronger strength due to the high shear flow of the tip leakage jet. The hub passage vortex is stretched and thus has a larger size. Finally, the tip leakage vortex and the hub passage vortex merge into one vortex with a reduction of the vorticity in both vortices.

In summary, the vortex interaction of the tip leakage vortex and the passage vortex in the $\mathrm{S}-\mathrm{CO}_{2}$ turbine contains the interaction with both the tip passage vortex and the hub passage vortex. The interaction of the tip leakage vortex and the tip passage vortex is a process of vortex squeezing, while the interaction of the tip leakage vortex and the hub passage vortex is a process of vortex merge. The principle of the vortex interaction can be demonstrated in Figure 9, which is the schematic of the fundamental vortex structure both in the gas turbine and $\mathrm{S}-\mathrm{CO}_{2}$ turbine. In the figure, the red circle marked with a positive sign in the center is the positive vortex and the blue circle marked with a negative sign in the center is the negative vortex.

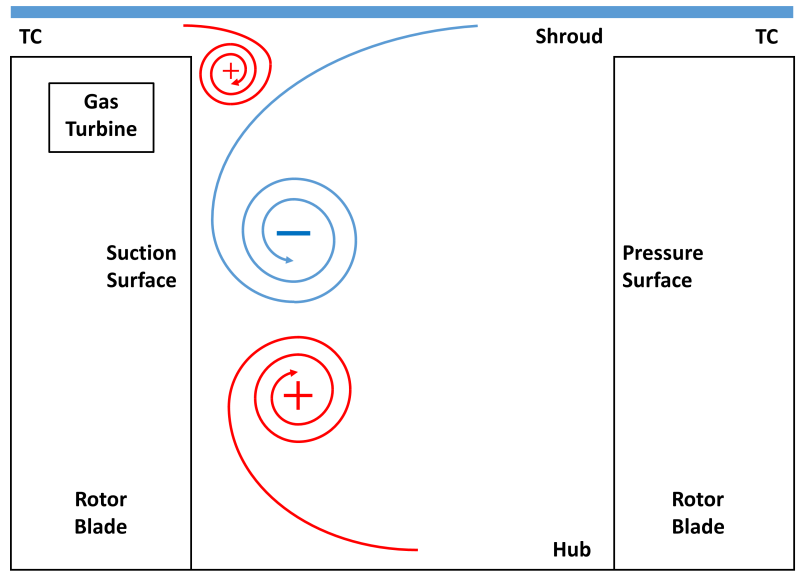

(a)

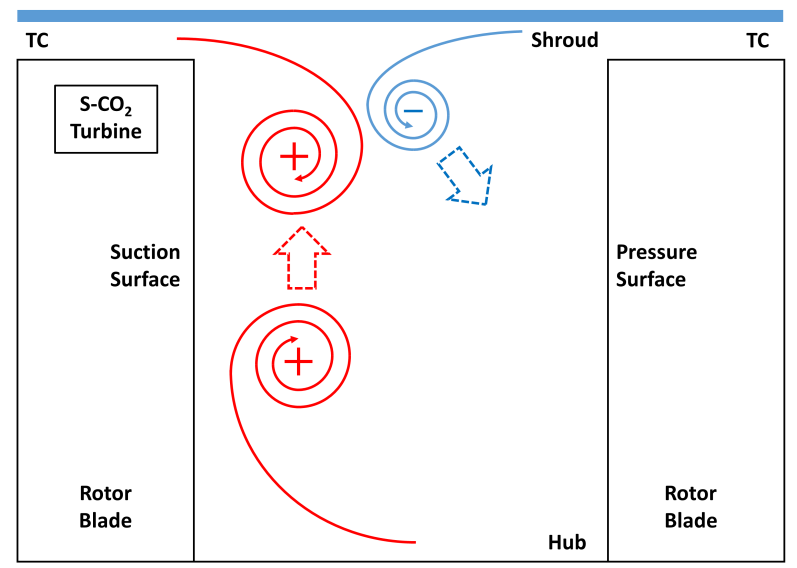

(b)

Figure 9. Schematic of fundamental vortex structure in different impellers. (a) Modeled flow status in gas turbine; (b) Modeled flow status in $\mathrm{S}-\mathrm{CO}_{2}$ turbine.

Figure $9 \mathrm{~b}$ displays the modeled flow status in the gas turbine. The tip passage vortex is formed near the shroud section and it expands itself when moving towards the negative spanwise direction in the passage. The hub passage vortex is formed near the hub section and also expands itself when moving towards the positive spanwise direction. These two vortices meet and collide with each other in the mid-span section as displayed in Figure 6. This collision can also be explained by the vortex rotational direction. The two passage vortices have opposite rotational directions, the flow direction on the interface is the same and the fluid particles thus cannot intrude into the other vortex. Moreover, the tip leakage vortex in the gas turbine is small and weak compared with the tip passage vortex, it is squeezed and pushed by the tip passage vortex and stays in the shroud section. 
However, the flow status displayed in the Figure $9 \mathrm{~b}$ is different. As is discussed previously, The tip leakage vortex is strong in the $\mathrm{S}-\mathrm{CO}_{2}$ turbine impeller as a result of the large tip gap and strong tip leakage jet. The tip passage vortex is pushed by the tip leakage vortex in the pitchwise direction and squeezed by the centrifugal force in the spanwise direction. On the contrary, the hub passage vortex is stretched and moves towards the outer casing with the effect of centrifugal force. With the dissipation of the tip passage vortex, the fully formed tip leakage vortex gets intruded by the hub passage vortex. These two positive vortices are weakened by each other and finally merge into one vortex at the impeller outlet.

\subsection{Energy Analysis Caused by Vortex Interaction}

The performance of the turbine is closely linked to its energy loss characteristics, after investigating the vortex flow patterns and associated flow physics in the $\mathrm{S}-\mathrm{CO}_{2}$ turbine, a deeper understanding of the energy loss mechanism is significant and will be discussed in this section. To analyze the energy loss that occurs in the flow field, the total pressure loss method was proposed and applied in turbomachinery in the last decades. Figure 10 presents the total pressure loss coefficient distributions in both D Turbine and C Turbine.

Mass-averaged total pressure loss coefficient

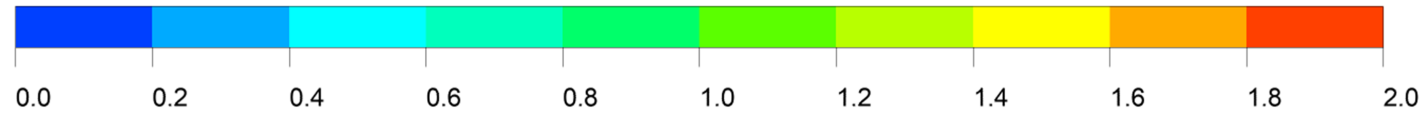

(a)
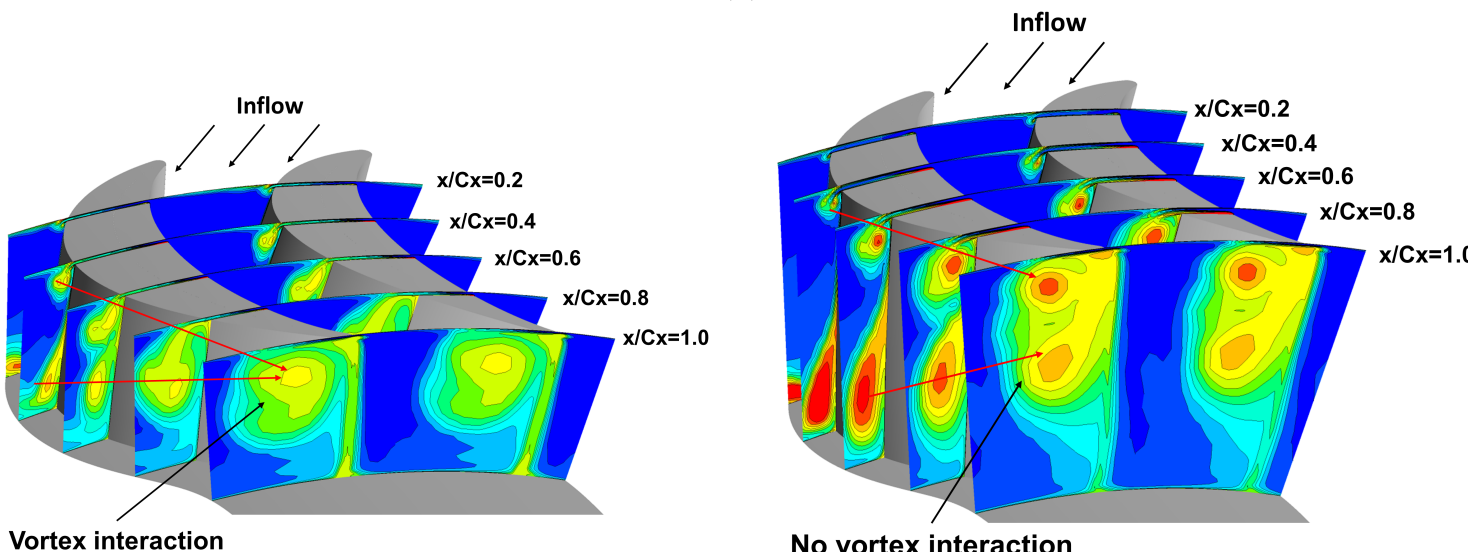

No vortex interaction

(b)

Figure 10. Mass-averaged total pressure coefficient in different turbine impeller passage. (a) Total pressure loss coefficient distribution in D Turbine; (b) Total pressure loss coefficient distribution in C Turbine.

As can be seen in Figure 10b, two energy loss caused loss coefficient increases can be recognized in the hub and shroud section. The positions and movements of the losses can be identified with the development of the hub passage vortex and the vortices in the shroud section. In the $C$ Turbine, although the hub passage vortex still moves towards the positive spanwise direction, it does not reach the shroud region as discussed in Figure 7a. As the loss in the shroud section gradually enhances and the loss in the mid-span section gradually dissipates, two loss area exists at the impeller outlet. Except for the interaction between the tip leakage vortex and the tip passage vortex, the interaction between the tip leakage vortex and the hup passage vortex could not be observed. While in Figure 10a, different energy variation processes can be seen. The high loss area caused by the tip vortices and the hub passage vortex is small and weak in the D Turbine. Starting from the location of $70 \%$ axial chord, the two losses move closer and merge into one part. With increasing in the size of the loss area, the peak value of the total pressure loss coefficient 
in the area decreases, especially the loss caused by the tip leakage vortex. A comparative analysis of the loss transfer process in the D Turbine and C Turbine indicates that the aerodynamic loss generated by the tip leakage vortex does not enhance itself with the development of the vortex in the D Turbine. On the contrary, the energy loss dissipates with the vortex interaction between the tip leakage vortex and the hub passage vortex.

Since the total pressure loss coefficient can only capture the internal energy variation without the vortex flow characteristics of the fluid. Considering the active vortex flows in the $\mathrm{S}-\mathrm{CO}_{2}$ turbine, the enstrophy dissipation method is employed in the present paper to calculate energy loss as well as capturing flow characteristics of the fluid. The total enstrophy and the enstrophy dissipation rate thus were calculated within the impeller passage and displayed in Figure 11.

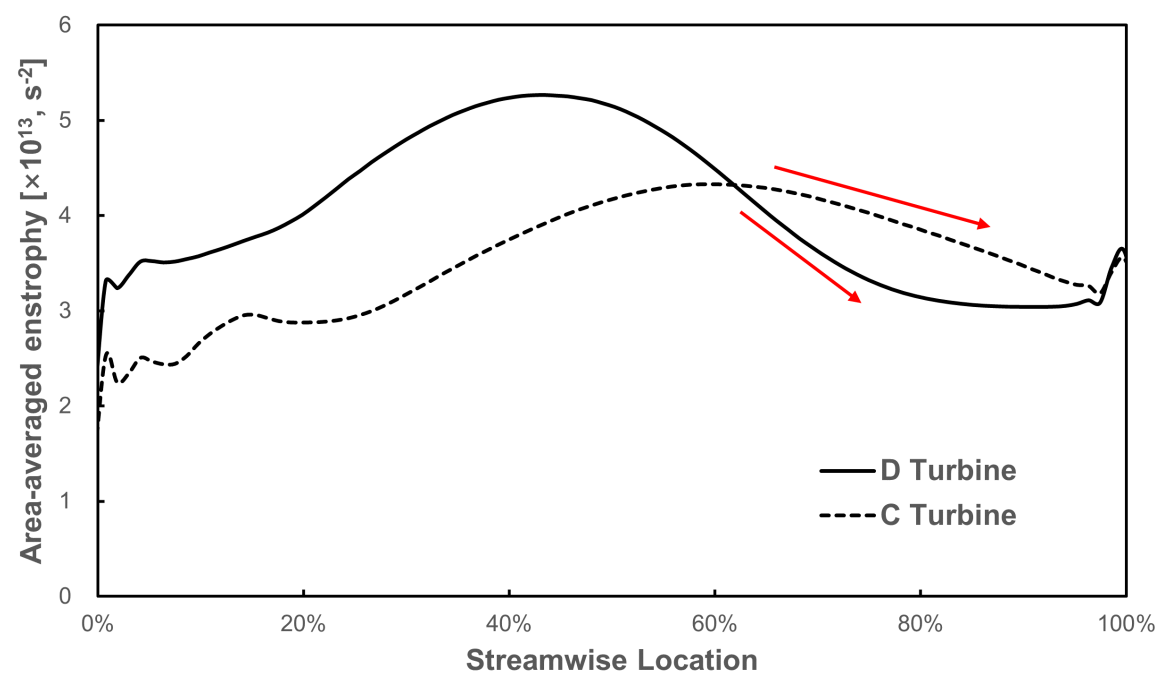

(a)

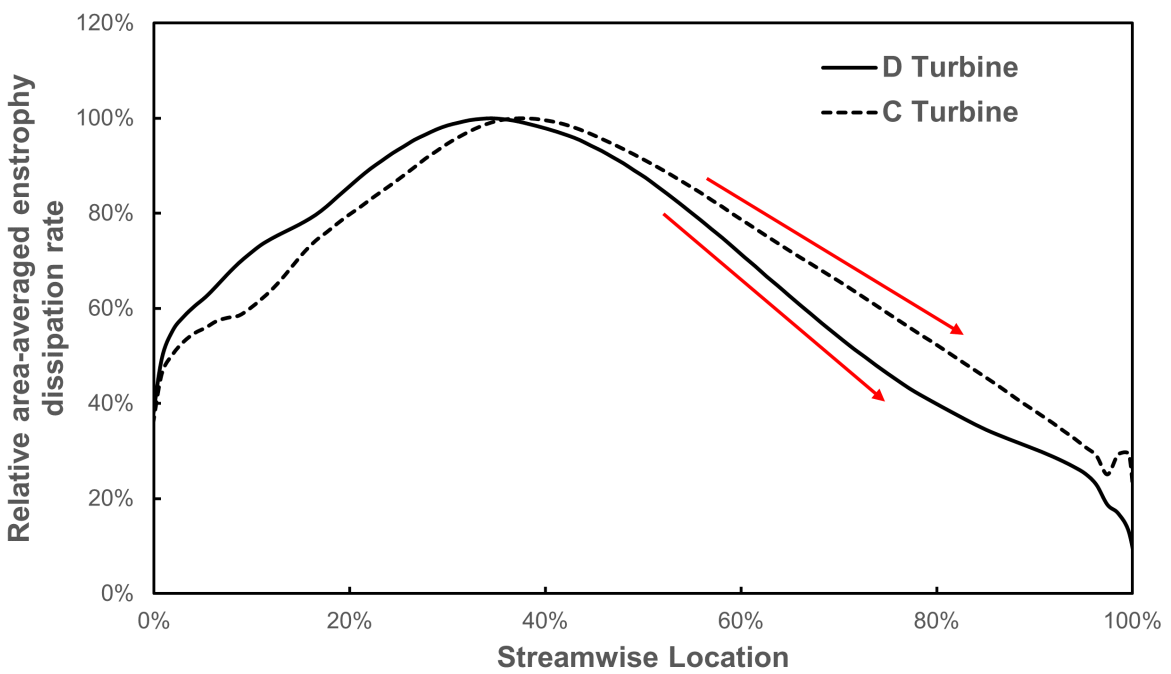

(b)

Figure 11. Energy loss comparison in D Turbine and C Turbine. (a) Streamwise area-averaged enstrophy variation; (b) Streamwise area-averaged enstrophy dissipation rate varation.

In these figures, what stands out is the variability of the relative enstrophy dissipation rate in both turbines. It can be clearly seen that the enstrophy dissipation rate in the $\mathrm{D}$ 
Turbine is higher in the streamwise front part of the impeller passage. At locations of $40 \%$ to $50 \%$ axial chord, the enstrophy dissipation rates in two turbines are similar and both reach their peak value. In the streamwise rear part, the enstrophy dissipation rate in the D Turbine drops dramatically and its value becomes smaller than the enstrophy dissipation rate in the $\mathrm{C}$ Turbine. This is the region where the vortex interaction between the tip leakage vortex, the tip passage vortex, and the hub passage vortex occurs. The enstrophy variation matches the enstrophy dissipation rate trend. The enstrophy is higher near the leading edge in the D Turbine as a result of more intense vortical motion in the small flow area. And the enstrophy starts to decrease when the tip leakage flow interacts with the tip passage vortex. The enstrophy falls to a low point at the location of around $80 \%$ axial chord, where the interaction between the tip leakage vortex and the hub passage vortex occurs. As is discussed in the previous part, both the vortex strength and the energy loss decrease with the vortex interaction, the enstrophy dissipation analysis thus confirms this assumption.

In general, the vortex interaction in the $\mathrm{S}-\mathrm{CO}_{2}$ turbine is a special vortex flow structure due to the fluid physical properties. The $\mathrm{S}-\mathrm{CO}_{2}$ turbine has a small size and a high rotational speed, it leads to a large impeller blade tip gap, high inertial force, and high centrifugal force. All of these features affect the vortices in the passage and cause the vortex interaction. Comprehensively considering the investigations of vortex patterns and energy loss in the $\mathrm{S}-\mathrm{CO}_{2}$ turbine, the vortex interaction is found not only changes the secondary flow patterns but also reduces downstream the vortex strength and associated aerodynamic losses in the passage. Similar findings on vortex interaction influence have been reported by Zhou et al. [50], who have conducted experimental and numerical studies on vortex dynamics in a turbine rotor cascade. They found that the vortex interaction between an external incoming swirling vortex and the tip leakage vortex could reduce the aerodynamic loss if two vortices had the same rotational direction. This exciting finding is significant to the $\mathrm{S}-\mathrm{CO}_{2}$ turbines since it illustrates that, with proper vortex inductions, the vortex interaction could be effectively utilized to design efficient $\mathrm{S}-\mathrm{CO}_{2}$ turbines.

\section{Conclusions}

The present investigations were carried out to explore the vortex flow patterns and the associated aerodynamic loss mechanism in a small-scale $\mathrm{S}-\mathrm{CO}_{2}$ axial turbine. A $160 \mathrm{~kW}$ $\mathrm{S}-\mathrm{CO}_{2}$ axial turbine was thus designed and simulated with validated numerical methods. Based on the simulation results, the following conclusions were drawn.

1. The geometric and operational features were found to play an important role in forming the vortice structure in the impellers. The small blade span, large tip clearance ratio, and low aspect ratio lead to the fully developed tip leakage vortex and passage vortices. These vortices are the dominant secondary flow in the passage, which generates the main aerodynamic losses.

2. A vortex interaction between the tip leakage vortex and the hub passage vortex was observed in the impeller passage, which is an unanticipated flow structure. Due to the large density of carbon dioxide and high rotational speed, the hub passage vortex is stretched by the large centrifugal force and thrown towards the outer casing. As a result, the tip leakage vortex was intruded by the hub passage vortex near the trailing edge, and downstream it mixes with the hub passage vortex and merges into one vortex at the impeller outlet. According to the authors' knowledge, this is the first time that the vortex interaction between the tip leakage vortex and the hub passage vortex is reported and explained in the turbine passage.

3. The energy loss characteristic of vortex interaction was analyzed with the enstrophy dissipation method. It was found that both the streamwise vorticity and viscous dissipation of these two vortices are reduced with vortex interaction. Correspondingly, the aerodynamic losses caused by these two vortices are also reduced compared with the case without vortex interaction. The potential payoff from this finding is that 
the vortex interaction could be utilized with proper methods to improve the $\mathrm{S}-\mathrm{CO}_{2}$ turbine performance.

Some aspects remain to be investigated in future research to fully understand the mechanism of the interaction between the tip leakage vortex and the hub passage vortex, such as unsteady flow instabilities and vortex interaction control. Future work will be devoted to further study these questions.

Author Contributions: Conceptualization, Q.Y. and W.Z.; Data curation, Q.Y.; Formal analysis, Q.Y. and W.Z.; Funding acquisition, W.Z. and C.M.; Investigation, W.Z.; Methodology, Q.Y.; Project administration, W.Z. and Y.Z.; Resources, C.M. and J.G.; Software, Q.Y.; Supervision, W.Z. and Y.Z.; Validation, W.Z. and C.M.; Writing—original draft, Q.Y.; Writing—review \& editing, Q.Y., W.Z., Y.Z., J.G. and W.W. All authors have read and agreed to the published version of the manuscript.

Funding: This work was supported by the National Key Research and Development Program of China (No. 2019YFB1901200), the National Natural Science Foundation of China (No. 51636005, No. 51806154, No. 52006156), Hubei Provincial Natural Science Foundation of China (No. 2018CFB317), and the Open Fund of Science and Technology on Thermal Energy and Power Laboratory (No. TPL2017AB008). The authors gratefully acknowledge them for their support for this work.

Institutional Review Board Statement: Not applicable.

Informed Consent Statement: Not applicable.

Conflicts of Interest: The authors declare no conflict of interest. The funders had no role in the design of the study; in the collection, analyses, or interpretation of data; in the writing of the manuscript, or in the decision to publish the results.

\section{References}

1. Rogalev, N.; Rogalev, A.; Kindra, V.; Komarov, I.; Zlyvko, O. Structural and Parametric Optimization of S-CO $\mathrm{CO}_{2} \mathrm{Nuclear}$ Power Plants. Entropy 2021, 23, 1079. [CrossRef] [PubMed]

2. Wu, C.; Wang, S.; Li, J. Exergoeconomic analysis and optimization of a combined supercritical carbon dioxide recompression Brayton/organic flash cycle for nuclear power plants. Energy Convers. Manag. 2018, 171, 936-952. [CrossRef]

3. Li, M.J.; Zhu, H.H.; Guo, J.Q.; Wang, K.; Tao, W.Q. The development technology and applications of supercritical $\mathrm{CO}_{2}$ power cycle in nuclear energy, solar energy and other energy industries. Appl. Therm. Eng. 2017, 126, 255-275. [CrossRef]

4. Wang, J.; Wang, J.; Lund, P.D.; Zhu, H. Thermal performance analysis of a direct-heated recompression supercritical carbon dioxide Brayton cycle using solar concentrators. Energies 2019, 12, 4358. [CrossRef]

5. Tafur-Escanta, P.; Valencia-Chapi, R.; López-Paniagua, I.; Coco-Enríquez, L.; Muñoz-Antón, J. Supercritical CO $\mathrm{CO}_{2}$ Binary Mixtures for Recompression Brayton s-CO 2 Power Cycles Coupled to Solar Thermal Energy Plants. Energies 2021, 14, 4050. [CrossRef]

6. Sun, E.; Xu, J.; Li, M.; Liu, G.; Zhu, B. Connected-top-bottom-cycle to cascade utilize flue gas heat for supercritical carbon dioxide coal fired power plant. Energy Convers. Manag. 2018, 172, 138-154. [CrossRef]

7. Mohammadi, K.; Ellingwood, K.; Powell, K. Novel hybrid solar tower-gas turbine combined power cycles using supercritical carbon dioxide bottoming cycles. Appl. Therm. Eng. 2020, 178, 115588. [CrossRef]

8. Ghotkar, R.; Stechel, E.B.; Ermanoski, I.; Milcarek, R.J. Hybrid Fuel Cell-Supercritical $\mathrm{CO}_{2}$ Brayton Cycle for $\mathrm{CO}_{2}$ SequestrationReady Combined Heat and Power. Energies 2020, 13, 5043. [CrossRef]

9. Schöffer, S.; Klein, S.; Aravind, P.; Pecnik, R. A solid oxide fuel cell- supercritical carbon dioxide Brayton cycle hybrid system. Appl. Energy 2020, 283, 115748. [CrossRef]

10. Roy, D.; Samanta, S.; Ghosh, S. Performance assessment of a biomass-fuelled distributed hybrid energy system integrating molten carbonate fuel cell, externally fired gas turbine and supercritical carbon dioxide cycle. Energy Convers. Manag. 2020, 211, 112740. [CrossRef]

11. Cho, S.K.; Lee, J.; Lee, J.I.; Cha, J.E. S-CO ${ }_{2}$ turbine design for decay heat removal system of sodium cooled fast reactor. In Turbo Expo: Power for Land, Sea, and Air; American Society of Mechanical Engineers: New York, NY, USA, 2016; Volume 49873, p. V009T36A006.

12. Utamura, M.; Hasuike, H.; Yamamoto, T. Demonstration test plant of closed cycle gas turbine with supercritical $\mathrm{CO}_{2}$ as working fluid. Tokyo Inst. Technol. 2010, 52, 459-465.

13. Utamura, M.; Hasuike, H.; Ogawa, K.; Yamamoto, T.; Fukushima, T.; Watanabe, T.; Himeno, T. Demonstration of supercritical $\mathrm{CO}_{2}$ closed regenerative Brayton cycle in a bench scale experiment. In Turbo Expo: Power for Land, Sea, and Air; American Society of Mechanical Engineers: New York, NY, USA, 2012; Volume 44694, pp. 155-164.

14. Ahn, Y.; Lee, J.; Kim, S.G.; Lee, J.I.; Cha, J.E. The design study of supercritical carbon dioxide integral experiment loop. In Turbo Expo: Power for Land, Sea, and Air; American Society of Mechanical Engineers: New York, NY, USA, 2013; Volume 55294, p. V008T34A003. 
15. Cho, J.; Shin, H.; Cho, J.; Baik, Y.J.; Choi, B.; Roh, C.; Ra, H.S.; Kang, Y.; Huh, J. Design, Flow Simulation, and Performance Test for a Partial-Admission Axial Turbine Under Supercritical $\mathrm{CO}_{2}$ Condition. In Turbo Expo: Power for Land, Sea, and Air; American Society of Mechanical Engineers: New York, NY, USA, 2018; Volume 51180, p. V009T38A019.

16. Cho, J.; Choi, M.; Baik, Y.J.; Lee, G.; Ra, H.S.; Kim, B.; Kim, M. Development of the turbomachinery for the supercritical carbon dioxide power cycle. Int. J. Energy Res. 2016, 40, 587-599. [CrossRef]

17. Cho, J.; Shin, H.; Ra, H.S.; Lee, G.; Roh, C.; Lee, B.; Baik, Y.J. Development of the supercritical carbon dioxide power cycle experimental loop in KIER. In Turbo Expo: Power for Land, Sea, and Air; American Society of Mechanical Engineers: New York, NY, USA, 2016; Volume 49873, p. V009T36A013.

18. Maxence, D.; Giuseppe, B.; Gabriel, H.; Norman, H.; Tassou, S.; Arthur, L. Design of a Single-Shaft Compressor, Generator, Turbine for Small-Scale Supercritical $\mathrm{CO}_{2}$ Systems for Waste Heat to Power Conversion Applications. In Proceedings of the 2nd European supercritical $\mathrm{CO}_{2}$ Conference, Essen, Germany, 30-31 August 2018; pp. 1-8.

19. Wang, Y.; Shi, D.; Zhang, D.; Xie, Y. Study on aerodynamic performance of a partial-admission supercritical carbon dioxide radial-inflow turbine. Therm. Turbine 2016, 45, 184-195.

20. Langston, L. Crossflows in a turbine cascade passage. J. Eng. Gas Turbines Power 1980, 102, 866-874. [CrossRef]

21. Sharma, O.; Butler, T. Predictions of endwall losses and secondary flows in axial flow turbine cascades. J. Turbomach. 1987, 109, 229-236. [CrossRef]

22. Goldstein, R.; Spores, R. Turbulent transport on the endwall in the region between adjacent turbine blades. J. Heat Transfer 1988, 110, 862-869. [CrossRef]

23. Wang, H.P.; Olson, S.J.; Goldstein, R.J.; Eckert, E.R. Flow visualization in a linear turbine cascade of high performance turbine blades. J. Turbomach. 1997, 119, 1-8. [CrossRef]

24. Sjolander, S.A. Secondary and Tip-Clearance Flows in Axial Turbines; Von Karman Institute for Fluid Dynamics: Rhode St. Genese, Belgium, 1997.

25. Yamamoto, A. Endwall flow/loss mechanisms in a linear turbine cascade with blade tip clearance. J. Turbomach. 1989, 111, 264-275. [CrossRef]

26. Tallman, J.; Lakshminarayana, B. Numerical simulation of tip leakage flows in axial flow turbines, with emphasis on flow physics: Part I-effect of tip clearance height. J. Turbomach. 2001, 123, 314-323. [CrossRef]

27. Dreyer, M.; Decaix, J.; Münch-Alligné, C.; Farhat, M. Mind the gap-tip leakage vortex in axial turbines. In IOP Conference Series: Earth and Environmental Science; IOP Publishing: Bristol, UK, 2014; Volume 22, p. 052023.

28. Dreyer, M.; Decaix, J.; Münch-Alligné, C.; Farhat, M. Mind the gap: A new insight into the tip leakage vortex using stereo-PIV. Exp. Fluids 2014, 55, 1-13. [CrossRef]

29. Kacker, S.; Okapuu, U. A mean line prediction method for axial flow turbine efficiency. J. Eng. Gas Turbines Power 1982, 104, 111-119. [CrossRef]

30. Yaras, M.; Sjolander, S. Prediction of tip-leakage losses in axial turbines. J. Turbomach. 1992, 114, 204-210. [CrossRef]

31. Denton, J.D. Loss Mechanisms in Turbomachines; American Society of Mechanical Engineers: New York, NY, USA, 1993; Volume 78897.

32. Han, W.; Wang, Y.; Feng, Z.; Li, H.; Yao, M.; Zhang, Y. Study on Flow Characteristics of a Turbulent Boundary Layer and Vortex Structure of High Pressure Guide Vanes in SCO 2 Turbines. J. Therm. Sci. 2019, 28, 571-584. [CrossRef]

33. Uusitalo, A.; Grönman, A. Analysis of Radial Inflow Turbine Losses Operating with Supercritical Carbon Dioxide. Energies 2021, 14, 3561. [CrossRef]

34. Tu, J. Design and Clearance Flow Mechanism Analysis of a Supercritical $\mathrm{CO}_{2}$ Expansion Turbine. Master's Thesis, Tsinghua University, Beijing, China 2018.

35. Ying, Q.; Zhuge, W.; Zhang, Y.; Qian, Y.; Zhou, D.; Tao, M.; Yang, L. Aerodynamic design and numerical analysis of a multi-stage axial turbine with S-CO 2 Brayton cylce. Therm. Power Gener. 2020, 49, 164-172 .

36. Du, Q.; Zhang, D. Numerical investigation on flow characteristics and aerodynamic performance of a 1.5-stage $\mathrm{SCO}_{2}$ axial-inflow turbine with labyrinth seals. Appl. Sci. 2020, 10, 373. [CrossRef]

37. Du, Q.; Zhang, L.; Zhang, D.; Xie, Y. Numerical investigation on flow characteristics and aerodynamic performance of shroud seal in a supercritical $\mathrm{CO}_{2}$ axial-flow turbine. Appl. Therm. Eng. 2020, 169, 114960. [CrossRef]

38. Qi, J.; Reddell, T.; Qin, K.; Hooman, K.; Jahn, I.H. Supercritical $\mathrm{CO}_{2}$ radial turbine design performance as a function of turbine size parameters. J. Turbomach. 2017, 139, 081008. [CrossRef]

39. Qi, J. Development and Application of Simulation Tools for Supercritical Carbon Dioxide Radial Inflow Turbine. Ph.D. Thesis, University of Queensland, Brisbane, Australia, 2019.

40. Keep, J.A.; Jahn, I.H. Numerical loss investigation of a small scale, low specific speed supercritical $\mathrm{CO}_{2}$ radial inflow turbine. J. Eng. Gas Turbines Power 2019, 141, 091003. [CrossRef]

41. Wang, Y.; Li, J.; Zhang, D.; Xie, Y. Numerical Investigation on Aerodynamic Performance of $\mathrm{SCO}_{2}$ and Air Radial-Inflow Turbines with Different Solidity Structures. Appl. Sci. 2020, 10, 2087. [CrossRef]

42. Salah, S.I.; Khader, M.A.; White, M.T.; Sayma, A.I. Mean-line design of a supercritical $\mathrm{CO}_{2}$ micro axial turbine. Appl. Sci. 2020, 10, 5069. [CrossRef]

43. Hunt, J.; Wray, A.; Moin, P. Eddies, Stream, and Convergence Zones in Turbulent Flows; Center for Turbulence Research CTR-S88; Stanford University: Stanford, CA, USA, 1988; pp. 193-208. 
44. Glassman, A.J. Turbine Design and Application; Scientific and Technical Information Office, National Aeronautics and and Space Administration: Washington, DC, USA, 1973; Volume 290.

45. Florian, R.M. Two-equation eddy-viscosity turbulence models for engineering applications. AIAA J. 1994, 32, $1598-1605$.

46. ANSYS. ANSYS CFX-Solver Modeling Guide; ANSYS: Canonsburg, PA, USA, 2020.

47. Lemmon, E.; Ian, H.B.; Huber, M.; McLinden, M. NIST Standard Reference Database 23: Reference Fluid Thermodynamic and Transport Properties-REFPROP, Version 10.0, National Institute of Standards and Technology; Standard Reference Data Program; NIST: Gaithersburg, MD, USA, 2018.

48. Huang, G.; Shu, G.; Tian, H.; Shi, L.; Zhuge, W.; Tao, L. Experiments on a small-scale axial turbine expander used in $\mathrm{CO}_{2}$ transcritical power cycle. Appl. Energy 2019, 255, 113853. [CrossRef]

49. Huang, G.; Shu, G.; Tian, H.; Shi, L.; Zhuge, W.; Zhang, J.; Atik, M.A.R. Development and experimental study of a supercritical $\mathrm{CO}_{2}$ axial turbine applied for engine waste heat recovery. Appl. Energy 2020, 257, 113997. [CrossRef]

50. Zhou, K.; Zhou, C. Aerodynamic interaction between an incoming vortex and tip leakage flow in a turbine cascade. J. Turbomach. 2018, 140, 111004. [CrossRef] 